\title{
Photovoltaic Cz Silicon Module Improvements
}

\section{Annual Technical Progress Report, 9 November 1995 - 8 November 1996}

NREL technical monitor: R. Mitchell

\author{
R.R. King, K.W. Mitchell, \\ and T.L. Jester \\ Siemens Solar Industries \\ Camarillo, California
}

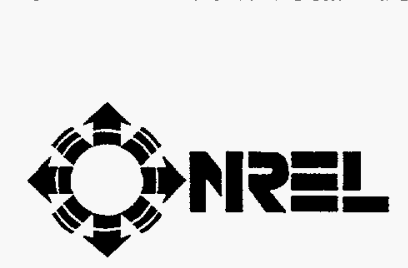

\section{MASTER}

National Renewable Energy Laboratory

1617 Cole Boulevard

Golden, Colorado 80401-3393

A national laboratory of the U.S. Department of Energy

Managed by Midwest Research Institute for the U.S. Department of Energy

under Contract No. DE-AC36-83CH10093

Prepared under Subcontract No.ZAF-5-14271-12 February 1998 
This publication was reproduced from the best available camera-ready copy submitted by the subcontractor and received no editorial review at NREL.

\section{NOTICE}

This report was prepared as an account of work sponsored by an agency of the United States govemment. Neither the United States government nor any agency thereoi, nor any of their employees, makes any warranty, express or implied, or assumes any legal liability or responsibility for the accuracy, completeness, or usefuiness of any infomation, apparatus, product, or process disclosed, or represents that its use would not infringe privately owned rights. Reference herein to any specific commercial product, process, or service by trade name, trademark, manufacturer, or otherwise does not necessarily constitute or imply its endorsement, recommendation, or favoring by the United States govemment or any agency thereof. The views and opinions of authors expressed herein do not necessarily state or reflect those of the United States government or any agency thereof.

Available to DOE and DOE contractors from:

Office of Scientific and Technical Information (OSTI)

P.O. Box 62

Oak Ridge, TN 37831

Prices available by calling (423) $576-8401$

Available to the public from:

National Technical Information Service (NTIS)

U.S. Department of Commerce

5285 Port Royal Road

Springfield, VA 22161

(703) $487-4650$ 


\section{DISCLAIMER}

Portions of this document may be illegible electronic image products. Images are produced from the best available original document. 


\section{Preface}

This report describes work done by Siemens Solar Industries (SSI) from November 9, 1995 to November 8, 1996 during Phase I of a three-phase Photovoltaic Manufacturing Technology (PVMaT 4A) subcontract from DOE/NREL. The work focuses on improvements in the cost per watt of $\mathrm{Cz}$ silicon photovoltaic modules through detailed understanding of their cost structure, module design to minimize cost per watt, measures to improve manufacturing yield and productivity, and manufacturing control systems to improve module reliability. The overall project goal is a reduction of $\mathrm{Cz}$ silicon module cost per watt of $18 \%$ at the end of the three phases of the subcontract.

\section{Acknowledgments}

Many people have contributed to the work under this contract. Thanks are due especially to Rick Mitchell, NREL technical monitor, to Ruben Balanga, Dave Bender, Eberth Covarrubia, Mark Crowder, Heinrich Eichermüller, Chet Farris, Bryan Fickett, Jean Hummel, Dave Jeffrey, Waltraut Klein, Greg Mihalik, Alex Mikonowicz, Jeff Nickerson, Ken Sandland, Ted Scheidegger, Maria Tsimanis, Von Walters, Elena Woodard, Eugene Yamamoto, and others in the Engineering, Quality, Manufacturing, and Finance groups at SSI.

This work was funded in part by DOE/NREL Subcontract \# ZAF-5-14271-12. 


\section{Summary}

Work focused on reducing the cost per watt of $\mathrm{Cz}$ silicon photovoltaic modules under Phase I of Siemens Solar Industries' DOE/NREL PVMaT 4A subcontract is described. Module cost components are analyzed and solutions to high-cost items are discussed in terms of specific module designs. The approaches of using larger cells and modules to reduce per-part processing cost, and of minimizing yield loss are particularly leveraging. Yield components for various parts of the fabrication process and various types of defects are shown, and measurements of the force required to break wafers throughout the cell fabrication sequence are given. The most significant type of yield loss is mechanical breakage. The implementation of statistical process control on key manufacturing processes at Siemens Solar Industries is described. Module configurations prototyped during Phase I of this project and scheduled to begin production in Phase II have a projected cost per watt reduction of $19 \%$. 


\section{Table of Contents}

Preface

Acknowledgments

ii

Summary

iii

Table of Contents

iv

List of Figures

Introduction

Program Goals

Approaches

Module Cost Analysis and Design 5

Module Cost Drivers $\quad 5$

$\begin{array}{ll}\text { Solutions to Module Cost } & 10\end{array}$

Model of Cost-per-Watt Dependence on Module Size 11

$\begin{array}{ll}\text { Specific Module Designs } & 13\end{array}$

$\begin{array}{ll}\text { Specific Improvements in Material Procurement and Utilization } & 14\end{array}$

$\begin{array}{ll}\text { Yield and Productivity Improvements } & 16\end{array}$

$\begin{array}{ll}\text { Types of Yield Loss } & 16\end{array}$

$\begin{array}{ll}\text { Breakage Force Studies } & 17\end{array}$

$\begin{array}{lr}\text { Mechanical Yield Experiments } & 18\end{array}$

Specific Measures to Increase Yield 23

Wafering 23

Cell Fabrication $\quad 24$

Module Fabrication $\quad 27$

Overall Yield Improvement in Wafering, Cell, and Module Areas 27

$\begin{array}{ll}\text { Specific Measures to Increase Productivity } & 28\end{array}$ 
Manufacturing Systems to Improve Module Reliability

Conclusions

References 


\section{List of Figures}

Figure 1. Cost/watt by process area, normalized to total $\$ N$, with cost of yield loss allocated to process area in which production must be increased in order to make up for yield loss.

Figure 2. Cost/watt by process area, normalized to total $\$ W$, with cost of yield loss allocated to area in which yield loss occured.

Figure 3. Ingot manufacturing costs per module watt for the case of $100 \%$ yield and the cost/watt of ingot yield loss.

Figure 4. Wafer manufacturing costs per module watt for the case of $100 \%$ yield and the cost/watt of wafer yield loss.

Figure 5. Cell manufacturing costs per module watt for the case of $100 \%$ yield and the cost/watt of cell yield loss.

Figure 6. Module manufacturing costs per module watt for the case of $100 \%$ yield, showing the large contribution of direct materials, and the cost/watt of module yield loss.

Figure 7. Cost/watt for direct material in the module fabrication area.

Figure 8. Dependence of module direct material costs and direct labor costs, for a module aspect ratio of 2 , and the assumptions described in the text.

Figure 9. SM110 module with $72103-\mathrm{mm}$ semi-square cells reduces $\$ / \mathrm{W}$ contribution of the frames and the junction box.

Figure 10. Large-area SM100 prototype module using 150-mm-diameter cells has a reduced cell contribution to $\$ \mathrm{~W}$, as well as reduced frame and junction box $\$ / W$ components.

Figure 11. Schematic of PowerMax junction box combining improved flexibility of use and lower cost per module watt.

Figure 12. Yield loss by process area. Due to the value added at each step in the process, yield loss in the module area is especially costly.

Figure 13. Yield loss by type of defect. Wafer breakage is by far the dominant loss mechanism for the wafering, cell fabrication, and module fabrication areas. 
Figure 14. Wafer breakage force of multicrystalline-Si (mc-Si) and SSI CZ Si, as measured by a stylus for wafers resting on two horizontal rails. The error bars indicate \pm 1 standard deviation in the data.

Figure 15. Mechanical yield of multicrystalline-Si (mc-Si) afers from Vendor $\mathrm{A}$, in SSI cell fabrication process.

Figure 16. Mechanical yield of multicrystalline-Si (mc-Si) wafers from Vendor B, in SSI cell fabrication process.

Figure 17. Electrical distribution for $S S I C z$ and mc-Si substrates. $I_{v r}$ is the cell current at a rated voltage of $0.484 \mathrm{~V}$, and is proportional to the cell power at that fixed voltage.

Figure 18. Comparison of cell electrical parameters for multicrystalline-Si and SSI Cz.

Figure 19. SPC chart of 125-mm wafer breakage in the first four process steps in cell fabrication. The downward jog in average breakage and range coincides with greater operator awareness of the breakage yield problem and greater visibility of the data, as described in the text.

Figure 20. SPC charting of emitter sheet resistance after diffusion.

Figure 21. Charting of automatic soldering yield provides feedback mechanism to gauge the effect of process changes. 


\section{Introduction}

\section{Program Goals}

The Photovoltaic Manufacturing Technology (PVMaT) project is sponsored by the U.S. Department of Energy (DOE) through the National Renewable Energy Laboratory (NREL) in order to assist the photovoltaics industry in improvement of module manufacturing, and reduction of module manufacturing cost. The objective of the DOE/NREL PVMaT subcontract with Siemens Solar Industries (SSI) is to continue the advancement of Siemens Solar Industries' photovoltaic manufacturing technology in order to achieve an $18 \%$ reduction in module cost per watt at the end of three phases of work, with each phase lasting a year as shown in Table 1. Phase I of this subcontract began in November 1995. The approaches for reaching this cost reduction goal are to analyze existing module cost structure and explore new module designs and materials, investigate the reduction of labor and improvement of yield, and to implement statistical process control (SPC) in module manufacturing.

Table 1. Goals of Siemens Solar Industries' PVMaT 4A Subcontract from DOE/NREL.

\begin{tabular}{|c|c|c|c|}
\cline { 2 - 4 } \multicolumn{1}{c|}{} & Phase I & Phase II & Phase III \\
\hline $\begin{array}{c}\text { New module } \\
\text { designs to reduce } \\
\$ N W\end{array}$ & $\begin{array}{c}6 \% \text { reduction in } \\
\text { module } \$ W\end{array}$ & $\begin{array}{c}12 \% \text { reduction in } \\
\text { module } \$ N\end{array}$ & $\begin{array}{c}18 \% \text { reduction in } \\
\text { module } \$ W\end{array}$ \\
\hline $\begin{array}{c}\text { Improvement of } \\
\text { yields and reduction } \\
\text { of labor }\end{array}$ & $\begin{array}{c}5 \% \text { improvement } \\
\text { in module mfg. yield } \\
5 \% \text { increase in } \\
\text { module mfg. } \\
\text { productivity }\end{array}$ & $\begin{array}{c}10 \% \text { improvement } \\
\text { in module mfg. yield } \\
10 \% \text { increase in } \\
\text { module mfg. } \\
\text { productivity }\end{array}$ & $\begin{array}{c}15 \% \text { improvement } \\
\text { in module mfg. yield } \\
15 \% \text { increase in } \\
\text { module mfg. } \\
\text { productivity }\end{array}$ \\
\hline $\begin{array}{c}\text { Improvement of } \\
\text { module reliability }\end{array}$ & $\begin{array}{c}\text { Implement SPC on } \\
50 \% \text { of appropriate } \\
\text { mfg. processes }\end{array}$ & $\begin{array}{c}\text { Implement SPC on } \\
100 \% \text { of appropriate } \\
\text { mfg. processes }\end{array}$ & $\begin{array}{c}\text { Assessment of SPC } \\
\text { protocols, areas for } \\
\text { improvement }\end{array}$ \\
\hline
\end{tabular}

\section{Approaches}

The first step toward reducing the cost per watt at the module level is to gain a thorough understanding of the present factors which dominate cost. Armed with this knowledge, the cell and module designs can be optimized to minimize the costs of ingot, wafering, cell, and module fabrication, as described in the following sections. The themes of larger cells, larger modules, and match of wafer shape to ingot crosssection are simple but effective means of reducing the cost per watt of silicon photovoltaic modules. These strategies have taken concrete form in prototype modules fabricated during Phase I of this PVMaT contract, in preparation for manufacturing implementation at SSI in Phase II.

In several process steps, yield loss is the greatest single contributor to the module cost per watt. Unlike other types of cost components, such as direct materials, yield loss is not an intrinsic cost of the process, 
and thus this cost can potentially be driven to zero. Yield loss comes in many forms, such as lost crystal structure, off-spec resistivity, wafer thickness variation, insufficient wafer cleaning, cell breakage and its dependence on wafer thickness and other parameters, etc. Understanding the relative significance of the various sources of yield loss, and focusing resources on only the most serious yield loss mechanisms was the approach taken in Phase I of this contract.

Four strategies to increase manufacturing productivity at SSI have been used: 1) use of automation; 2) development of relationships with vendors to provide preassembled parts or preinspected materials; 3) critical reevaluation of staffing requirements of various process steps; and 4) improved efficiency of the internal logistics of material supply. Although in some process areas the number of hours of labor can be decreased even as the plant output in MW/year is being ramped up, increased production volume will still require other processes to be more heavily staffed. The most desirable situation is to retrain operators in process areas with reduced labor requirements for the jobs which scale with greater production volume. Thus the number of labor hours per MW can be reduced, while keeping a roughly constant labor pool, by virtue of the higher plant output.

The approach taken to improve SSI $\mathrm{Cz}$ silicon module reliability is one of increased control over manufacturing systems, including design and material procurement, in addition to manufacturing process parameters. Statistical process control of key steps in the fabrication sequence is a cornerstone of this strategy. Many of the steps required for certification under the ISO 9001 quality system directly address the issues of manufacturing control: written documentation of procedures and work instructions; training and certification of operators; measurement of process capability factors; calibration of measurement instrumentation used to control fabrication processes; and internal and external quality audits of manufacturing compliance. SSI received ISO 9001 certification during Phase I of this contract. 


\section{Module Cost Analysis and Design}

\section{Module Cost Drivers}

This section gives examples of the cost structure of module manufacturing at SSI. Once the most significant costs are known, strategies for reducing them are formulated and discussed. Finally, specific module designs that address these cost issues are presented. These improvements in module configuration have been introduced into production in the SSI Camarillo plant during Phase I of the contract, or exist as prototypes with production scheduled to start during Phase II.

Figure 1 shows the division of cost per watt at the module level among the four major process segments of wafered silicon solar cell fabrication: ingot growth; wafering; cell fabrication; and module fabrication. Module fabrication has the largest cost of these, and so is a reasonable area on which to focus efforts to reduce the overall cost per watt. However, costs in the other areas are also very significant contributors to the cost per watt at the module level, and must be addressed as well.

The costs in each process area in Figure 1 are divided to show the costs due to yield loss, the costs that would be incurred even if the yield were $100 \%$, and manufacturing overhead costs. Yield loss in a given process area requires that upstream processes increase their production volume, in order to make up for the lost material. Yield loss in the cell fabrication area, for instance, requires that more cells be produced to make up for the loss, and requires greater production volumes in the wafer and ingot areas as well, to provide raw materials for those cells. So yield loss in a given process increases the costs residing in the upstream processes as well. This is shown in Figure 1.

If the yield were $100 \%$ in each process area, the production volume in each area could be reduced while maintaining the same overall plant MW/year output. The costs in each process area would then be the height of the bars labeled $100 \%$ yield case in Figure 1, plus Mfg. overhead. The items summed under the $100 \%$ yield case are costs which increase if equipment is added to increase plant capacity (for instance, to make up for yield loss in downstream processes), in addition to material and labor costs that increase with increased production volume. These items are: direct material; indirect material; direct labor; indirect labor and fringe benefits; depreciation on capital equipment; maintenance of equipment; and building rent and utilities. Mfg. overhead consists of those costs which do not, to first order, increase when production volume is increased, but which are nevertheless directly associated with manufacturing. These items include the costs of manufacturing management, and the logistics, health \& safety, and quality assurance departments. Functions not directly related to manufacturing, such as the marketing $\&$ sales, or finance departments, are not included in Mfg. overhead.

Figure 2 shows an alternate way to group the costs of yield loss. Rather than group them in the process area which must bear the burden of increased volume to make up for lost production, as in Figure 1, Figure 2 lumps the yield loss costs in the process area for which the yield loss was incurred. Thus the cost of yield loss in the module area includes not only the cost of module fabrication, but also the costs of ingot, wafer, and cell fabrication required to replace the cells in the lost modules. The $100 \%$ yield case and $\mathrm{Mfg}$. overhead values remain as they were before in Figure 1. This is the convention followed for the cost of yield loss in the rest of the figures. 


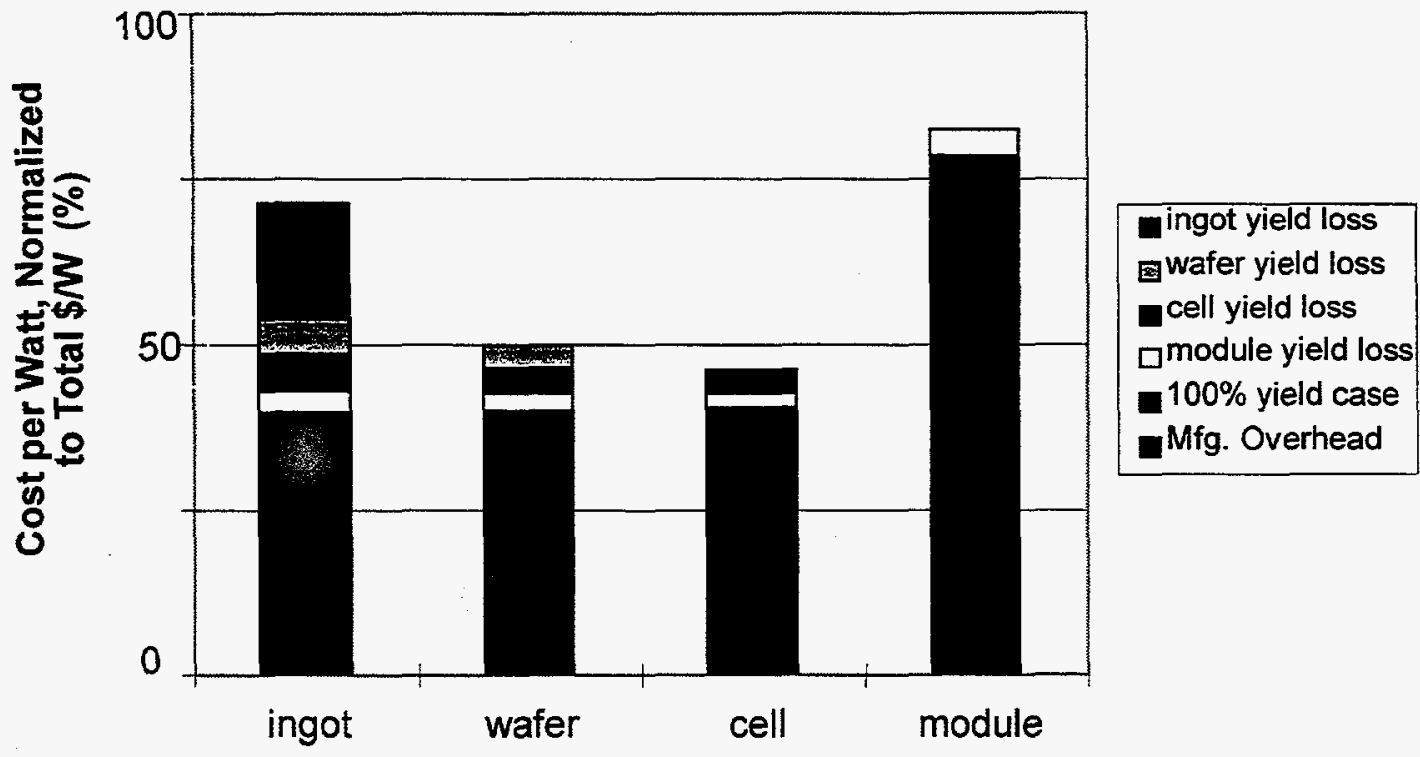

Process Area

Figure 1. Cost/watt by process area, normalized to total $\$ N$, with cost of yield loss allocated to process area in which production must be increased in order to make up for yield loss.

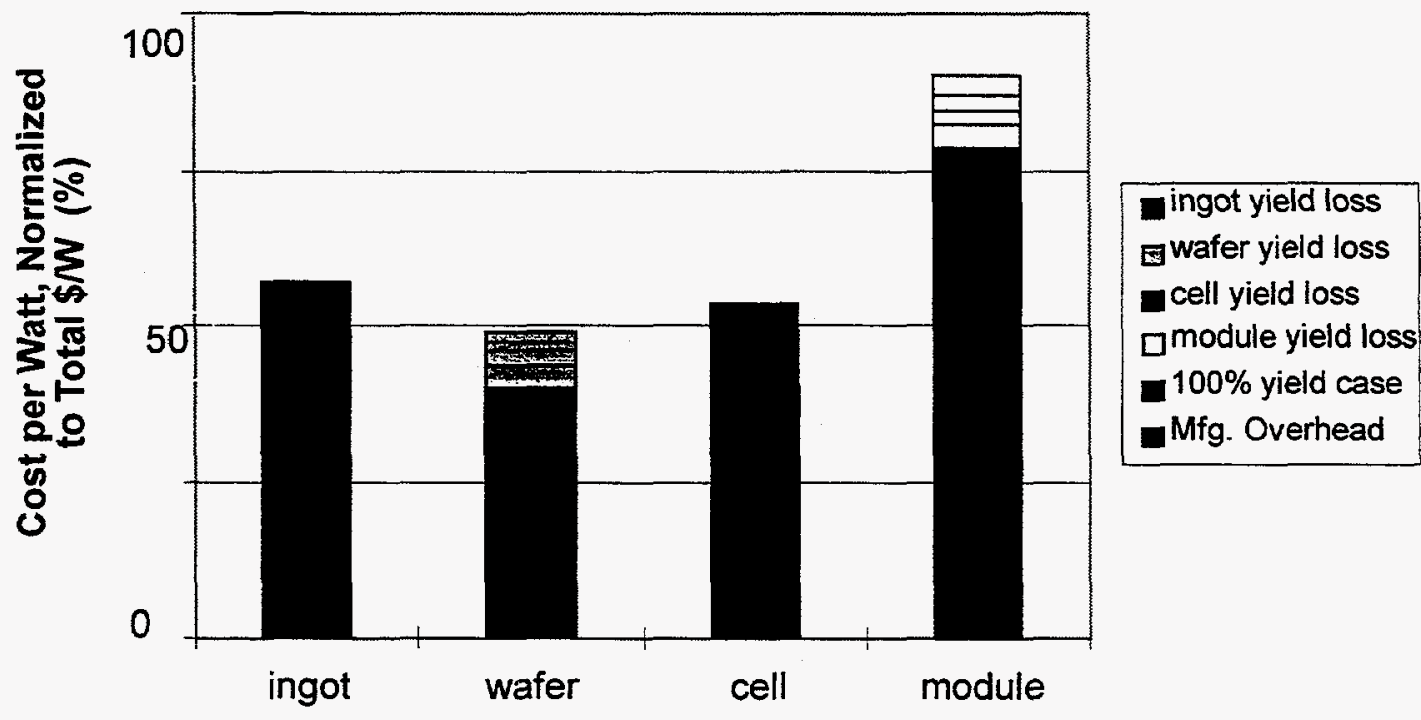

Process Area

Figure 2. Cost/watt by process area, normalized to total $\$ W$, with cost of yield loss allocated to area in which yield loss occured. 
It is instructive to break the $100 \%$ yield case down into its component parts and compare the magnitude of these constituent costs with the cost of yield loss. This is done in Figure 3-Figure 6. In the ingot growth area, yield loss is by far the dominant contributor to cost per watt at the module level, as can be seen in Figure 3. Significant steps have been taken to combat this loss, for example, specification and procurement of an acid cleaning line for silicon feedstock used in crystal growth at the end of Phase I. The magnitude of the yield loss cost is followed by direct and indirect materials costs in the ingot area. It should be noted that the direct materials costs include some purchased ingot, and so is not solely due to cost of Si feedstock. Indirect materials include such parts as quartz crucibles and graphite heaters. Although Si crystal growing is an energy-intensive process, the costs of utilities have been held fairly low in comparison to other cost components, due largely to the consolidation of crystal growth operations in Vancouver, WA where electricity rates are much lower than at the Camarillo, CA site.

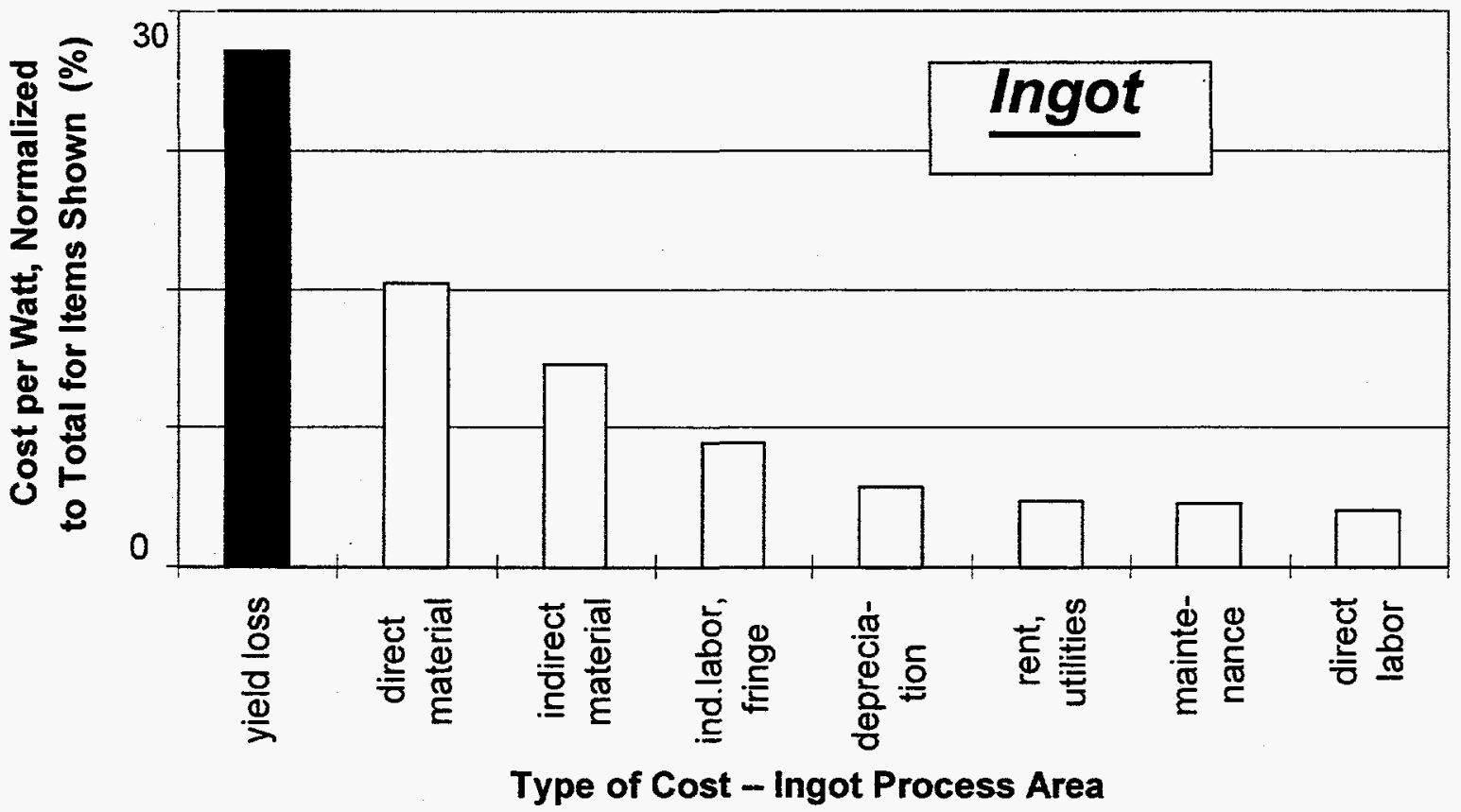

Figure 3. Ingot manufacturing costs per module watt for the case of $100 \%$ yield and the cost/watt of ingot yield loss.

Systematic exploration of wire saw parameters, such as wire tension and speed, and characterization of the properties of the silicon carbide and oil that make up the cutting slurry, have resulted in vastly improved understanding of the wire sawing process and correspondingly low yield loss. As shown in Figure 4, indirect materials, such as wire, carbide, oil, and solvent used to remove the slurry, are dominant costs in the wafering process area. Measures to reduce use of these indirect materials, such as cutting a greater number of ingots per wire saw run, often face a trade-off with wafering yield. 


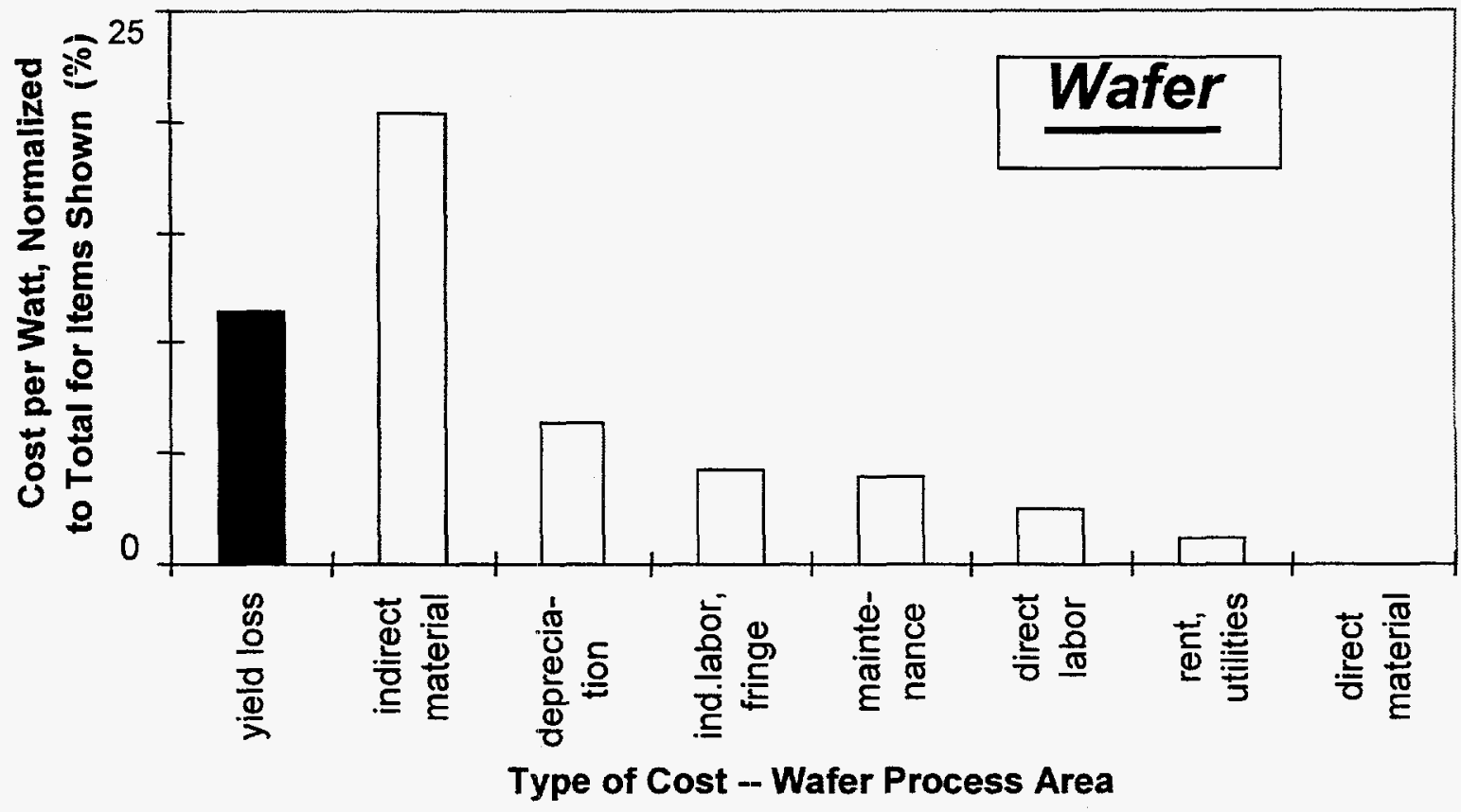

Figure 4. Wafer manufacturing costs per module watt for the case of $100 \%$ yield and the cost/watt of wafer yield loss.

In the cell fabrication area, yield loss stands out as the largest contributor to cost per watt, as can be seen in Figure 5. During Phase I the dominant cause of this yield loss was wafer breakage in the multiple automated and manual handling steps in the cell fabrication sequence. Therefore, the emphasis in Phase I to combat this loss was on identifying the fabrication steps in which breakage was greatest, strengthening feedback on mechanical yield to the operators who handle the wafers, and on understanding the dependence of force required to break a wafer on substrate and surface properties. Among the remaining costs per module watt in cell fabrication, the six next largest are fairly comparable in magnitude.

Direct materials such as glass, frames, interconnect ribbons, etc. are by far the largest component of cost per watt in the module fabrication area, as shown in Figure 6. Yield loss is the next largest cost; although the percentage of yield loss in the module area is fairly low, the costs of ingot, wafer, and cell fabrication are all folded into the yield loss cost per watt in the module area, elevating this cost. Indirect and direct labor are the two next largest cost components in the module area. While smaller than the cost of module direct materials, the yield and labor components may be more amenable to reduction for a given module design. 


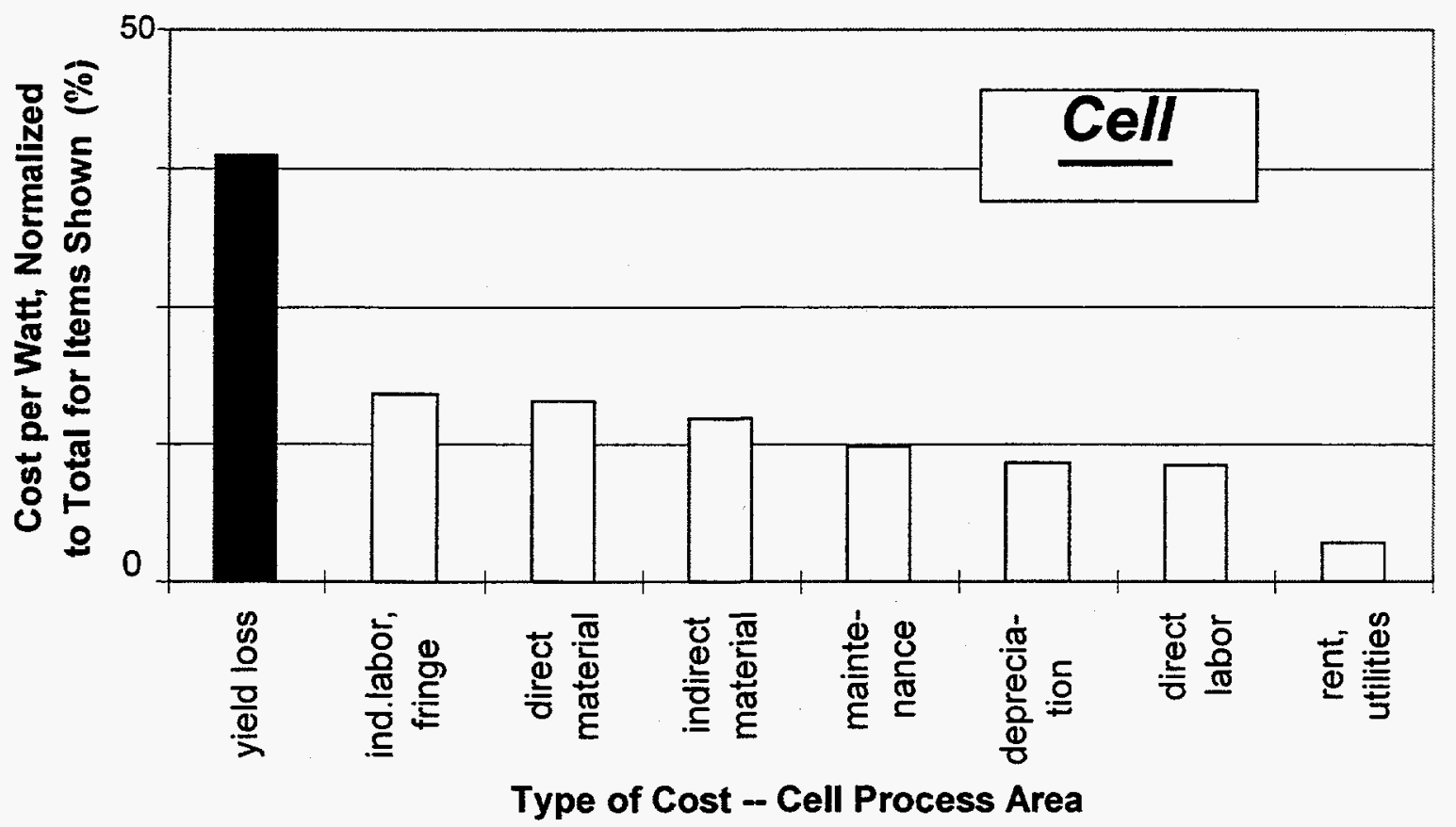

Figure 5. Cell manufacturing costs per module watt for the case of $100 \%$ yield and the cost/watt of cell yield loss.

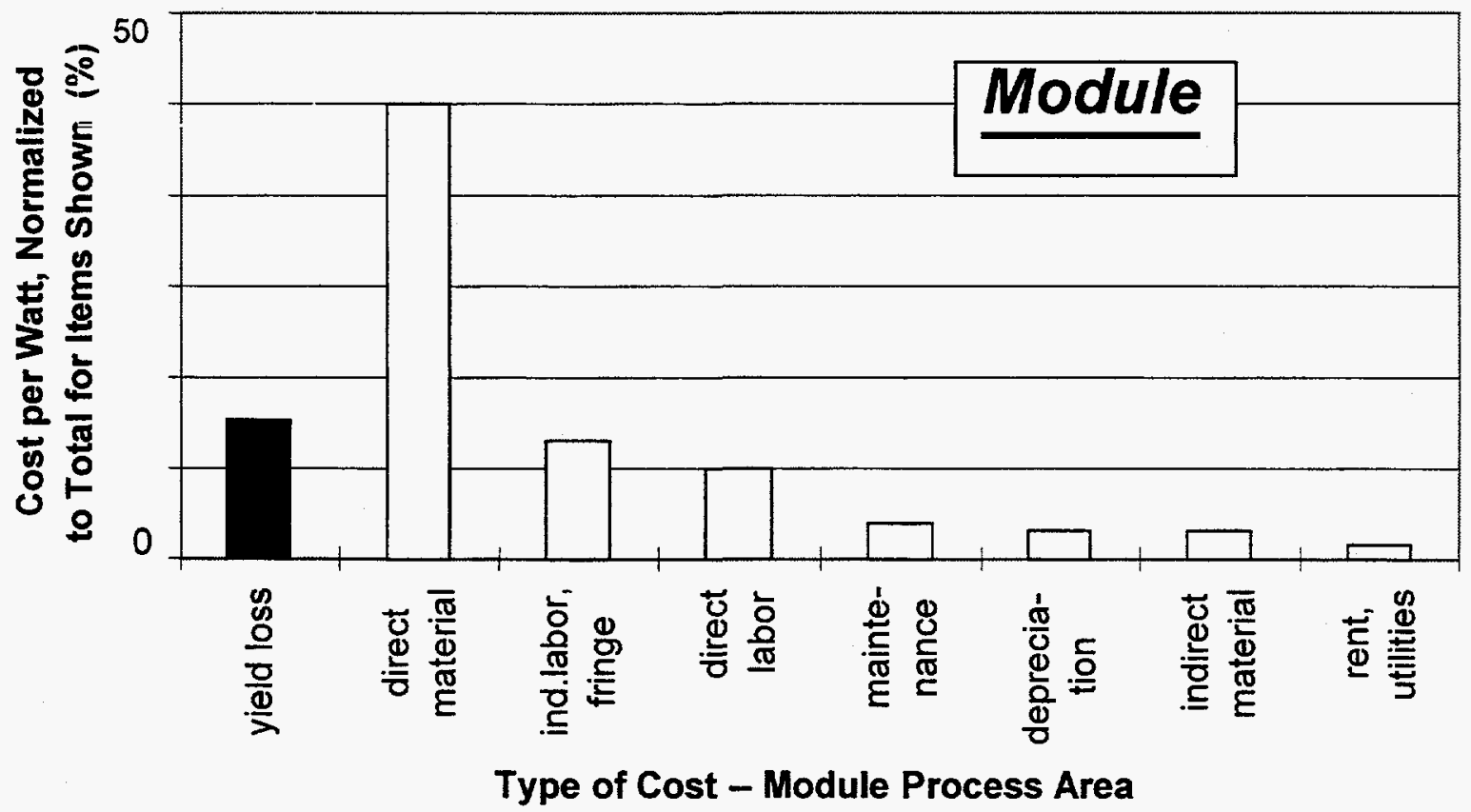

Figure 6. Module manufacturing costs per module watt for the case of $100 \%$ yield, showing the large contribution of direct materials, and the cost/watt of module yield loss. 

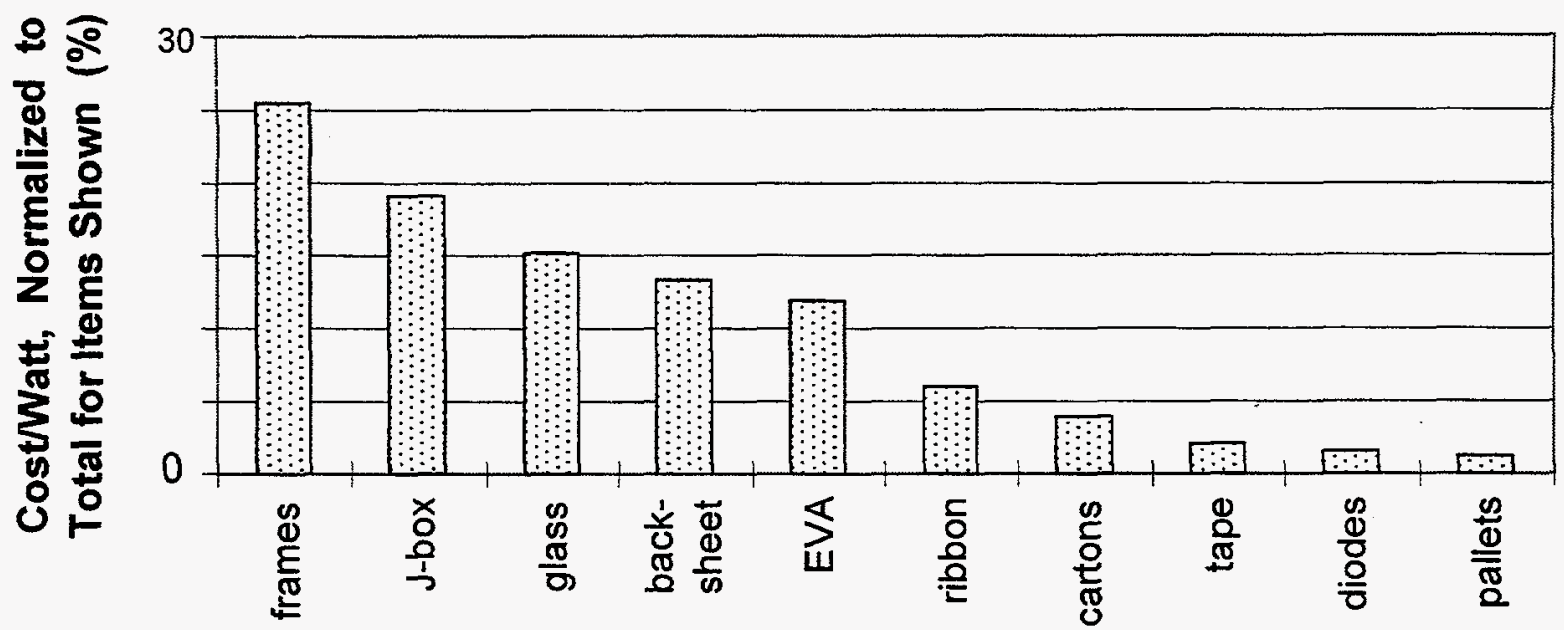

Type of Direct Material in Module Area

Figure 7. Cost/watt for direct material in the module fabrication area.

Resolving the detail in the module direct material costs, we see in Figure 7 that there are many contributors, but that the frames and junction boxes are the greatest module direct material costs. The next three largest cost components are proportional to the area of the module: glass, backsheet, and the ethylene vinyl acetate (EVA) sheets used to encapsulate the cells. Since the two direct materials with the largest cost, frames and junction boxes, do not scale with the module area, their contribution to module cost per watt can be reduced by increasing module size as described in the next section.

\section{Solutions to Module Cost}

Methods for reducing the cost per watt at the module level can be divided into at least three categories of reductions in: the cost of cells that go into the modules, the cost of module direct materials, and the cost of module manufacturing labor. Starting with the cost of cells, a principle used to great advantage in the integrated circuit industry is to increase the substrate size, thus producing a greater amount of the desired output (watts for solar cells) for each part processed. Another lesson from integrated circuit fabrication lines, as well as other types of manufacturing, is that yield is tremendously leveraging, particularly in processes with as many steps as there are between silicon feedstock and finished photovoltaic modules.

Several other issues are important for reducing cell cost. The cell shape should conform to the ingot in order to make the best use of the grown silicon. For $\mathrm{Cz} \mathrm{Si}$, this indicates round substrates. Decreasing cell material usage is a straightforward way to reduce cell costs, e.g., through the use of thinner wafers. Increasing the cell power, e.g., by reducing resistive losses, lowers the $\$ / W$ by increasing the denominator of this ratio.

The themes of using larger parts and increasing yield are quite general and apply to modules as well. With regard to the cost of module direct materials, increasing the module size lowers the perimeter-toarea ratio, thus reducing the $\$ / W$ contribution of the frames. Similarly, the cost of junction boxes can be spread out over a greater wattage by using larger modules. Simply finding less expensive materials and vendors for frames and junction boxes is always a valid method for reducing cost. The use of glass, 
EVA scale with the module area, but reduced sheet thicknesses can be used to conserve materials. As always, yield is highly leveraging for reducing direct materials costs.

For manufacturing direct labor, increased module size reduces the $\$ / W$ of all processing steps whose costs scale with the number of parts processed rather than with the module area. Automated assembly, e.g., the Spire automatic soldering equipment developed under another PVMaT subcontract, and semi-automated fixturing is important for managing the costs of a labor-intensive process like module fabrication. Once again, maintaining high yield is necessary for maximizing operator productivity and holding manufacturing labor costs low.

Most of the above strategies for reducing the cost per watt of $\mathrm{Cz} \mathrm{Si}$ photovoltaic modules have been employed during Phase I of this contract.

\section{Model of Cost-per-Watt Dependence on Module Size}

Based on the observation that many module material and labor costs do not increase as rapidly as the module area when the module is made larger, a model was developed to quantify these cost savings available through module design. Costs of the component materials and of the module fabrication labor were plugged into the model to calculate the cost per watt as a function of module size. This allows the module designer to see clearly at which point it is advantageous to increase module size, and at which point further size increases have diminishing returns. This analysis separates the benefits of increasing module size from the further benefits achievable with increased cell size and cell shape matched to the ingot cross section.

The module direct materials and direct labor components can be divided into three categories: costs which are proportional to the module area; costs which vary with the linear dimensions of the module; and costs which are constant with respect to module size. The model described here uses module aspect ratio $(\gamma=$ module length/module width) as a parameter, so that in terms of the module width $w$, module length is $\gamma w$, the perimeter length is $2(1+\gamma) \mathrm{w}$, and module area is $\gamma \mathrm{w}^{2}$.

Most photovoltaic modules include some inactive region around the module perimeter made up of the lamination materials without cells, to provide room for the circuit layout or for the framing scheme. The cost of the lamination materials used in this perimeter region scales with the length of the perimeter, since the width of the perimeter region is approximately constant with respect to module size. The size, shape, and spacing between cells in the module define a unit cell of module area. The area of this unit cell times the number of cells gives the area of the active region of the module, as opposed to the perimeter region. The module area, width, and length discussed above refer to the dimensions of this active region. The cost of lamination materials (glass, backsheet, and EVA) required to cover the active region of the module increases proportionally to module power as the module is made larger, and so increasing the module size does not affect this component of the cost/watt. Similarly, in this treatment with constant cell size, the costs of cell interconnect ribbon and solder are also proportional to the area of the active region, and therefore to the module power.

Module direct material costs which scale with the linear dimensions of the module are: the lamination materials in the perimeter region discussed above; the circuit busbars used to connect series strings of tabbed cells; the sealant material around the laminate perimeter; and the module frames. Since the cost of these items increases more slowly than the module area and the module power, larger modules will tend to decrease the contribution of these items to the cost per watt. Based on purchase price data, the cost of frames has a component which is proportional to length, and a component which is constant with respect to 
length. Finally, the junction box (including diodes, sealant, etc.), material used for circuit busbar isolation near the junction box, and the module label are independent of module size, so that an increase in module size has the greatest impact on these components of the cost/watt.

For the direct labor required to make modules from cells, the module fabrication sequence was divided into two major portions: 1) soldering cells into strings; and 2) assembling the module circuit from cell strings, lamination, and module finishing operations such as framing and testing. When considering a change in module size while keeping cell size constant, larger modules require that the number of cells to be soldered be increased in proportion to the module area. The cost of direct labor is assumed to be a constant times the length of soldered cell strings required, and for constant cell width, the length of strings is proportional to the area of the module. So the cost of direct labor required for cell stringing scales with the module area in this model, and therefore there are no reductions in soldering direct labor cost/watt as a result of increasing module size only. Note that if cell size is increased, then the cell width is larger, and more soldered cell area is gained per unit length of string soldered. So for an increase in cell size, the cost/watt of soldering can be decreased.

For the remainder of the module fabrication process (circuit assembly, lamination, and module finishing), it is probably too optimistic to assume that the direct labor costs will be proportional to the number of modules handled, regardless of the module size. However, many direct labor costs should increase more slowly than the module area as the module size increases. As an approximation, the direct labor costs in this area are taken to be proportional to the linear dimensions of the module, which increase more slowly than the area. When considering such operations as soldering tabbed cell strings to the circuit busbars, attaching the module frames, or transporting modules down a linear assembly line, this approximation of linear dependence on module dimensions seems plausible.

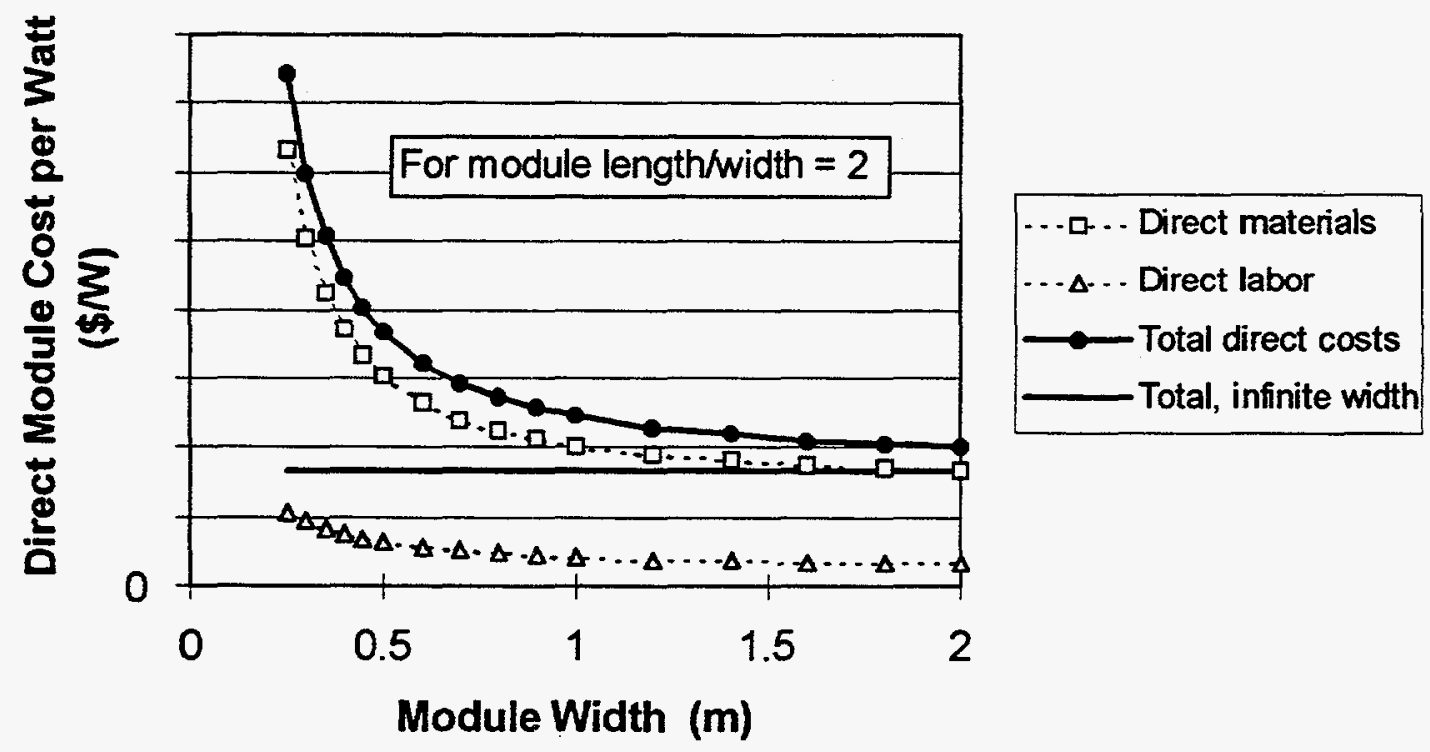

Figure 8. Dependence of module direct material costs and direct labor costs, for a module aspect ratio of 2 , and the assumptions described in the text. 
Figure 8 shows the dependence of direct materials and direct labor costs on the module width, calculated according to the guidelines described above, for a module aspect ratio of length/width $=2$. Other aspect ratios can be readily plugged into the model. The total direct cost/watt in the module area decreases rapidly as the module width is increased from $\sim 0.25$ to $0.5 \mathrm{~m}$, undergoes a gradual decline from about 0.5 to $1.0 \mathrm{~m}$, and changes only slowly for larger module widths. The asymptotic value of the module direct cost/watt as the module width becomes infinite is also shown on the graph. SSI modules are evolving from a width of $\sim 0.33 \mathrm{~m}$ to nearly $0.6 \mathrm{~m}$, primarily due to the issues represented by the above model.

\section{Specific Module Designs}

The strategy of building larger modules with the same size cell was used in manufacturing during Phase I of this contract. Figure 9 shows a schematic of an SM110 module with 72 103-mm semi-square cells, rather than the more usual 36. This type of laminate began production in the SSI Camarillo plant in August 1996. The larger module size and power $(110 \mathrm{~W})$ lower the $\$ / \mathrm{W}$ components from the frames, junction box, module manufacturing labor, etc., resulting in a $4 \%$ reduction in module $\$ / W$ relative to $36-$ cell modules.

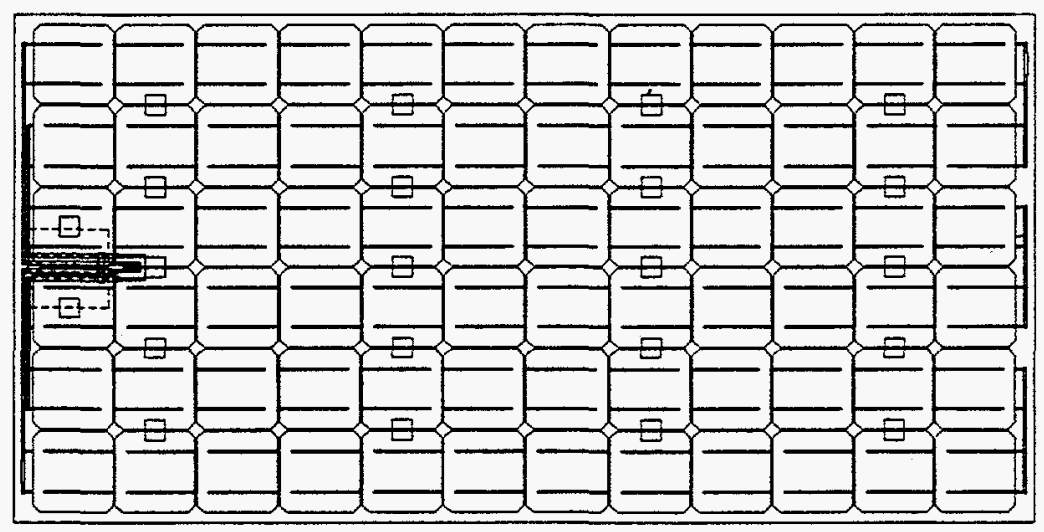

Figure 9. SM110 module with $72103-\mathrm{mm}$ semi-square cells reduces $\$ N$ contribution of the frames and the junction box.

Figure 10 shows a new module configuration that uses 150-mm round cells in a 36-cell package. Prototypes of this module have been built during Phase I of this contract and shipped to NREL. Much of the effort to reduce the cost/watt at the module level in Phase II focuses on the implementation a new product line based on $150-\mathrm{mm}$ round cells in production. The cost per watt is expected to be significantly lower for this type of module for a variety of reasons. The larger cell substrates used translate to an increase in surface area per wire saw run, and a reduction of wafer handling and cell fabrication equipment costs per watt for a given MW/year production level. The round shape of the 150-mm cell makes more efficient use of the $\mathrm{Cz}$ ingot by eliminating slabbing of the ingot. As described above, the large module size also means that module direct materials, module direct labor, and equipment costs per watt will be reduced for a given MW/year production level. All told, this module configuration with $150-\mathrm{mm}$ round cells is projected to be capable of a $19 \%$ reduction in cost per watt. 


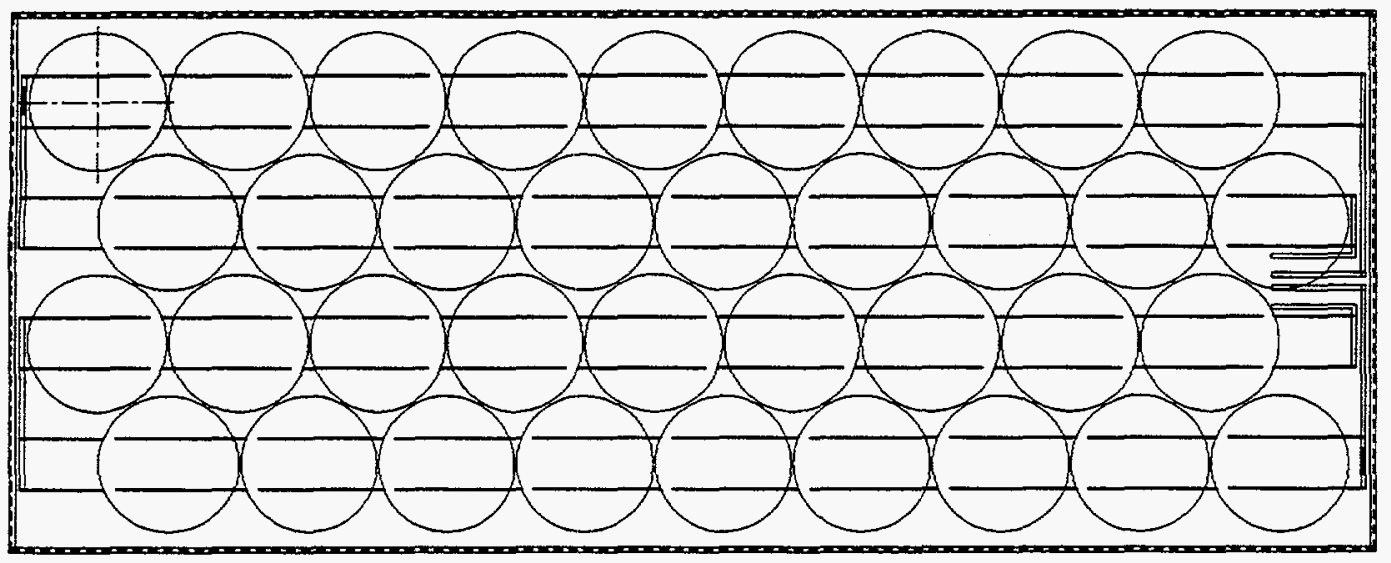

Figure 10. Large-area SM100 prototype module using 150-mm-diameter cells has a reduced cell contribution to $\$ \mathbb{W}$, as well as reduced frame and junction box $\$ \mathbb{N}$ components.

\section{Specific Improvements in Material Procurement and Utilization}

A straightforward and highly effective way to reduce the module cost per watt is through improved design or manufacturing of the component parts. Another clear but often overlooked form of cost/watt savings is through improved vendor relationships which allow greater efficiency for both the vendor and the photovoltaics manufacturer, e.g., fewer defective parts, streamlined return policy, lowered need for receiving inspection of component materials, reduced work in procress (WIP), etc. This section describes specific cost reductions of this sort that were achieved in Phase I.

As a result of consolidating SSI Cz crystal growth operations in the Vancouver, WA facility, electricity costs for Si ingot production were sharply reduced in Phase I. The energy-intensive process of $\mathrm{Cz}$ Si ingot growth had been split between the Vancouver, WA site, and Camarillo, CA, where the price of a $\mathrm{kWhr}$ from the electric utility is much higher than in the Pacific Northwest. Consolidation of the crystal growing operations in Vancouver was completed in Dec. 1995.

Due to the polysilicon feedstock shortage that impacted the Si photovoltaics industry during Phase I, both the cost of feedstock and the availability of normal types of feedstock were adversely affected. Using alternative forms of feedstock when more traditional types were no longer available increased costs through greater crystal growing yield loss, since the procedures for growing with the different feedstock types had not yet been developed. However, several successes came out of this inhospitable cost environment. Boron dopant schedules were developed to expand the usable range of Si feedstock to either $\mathrm{p}$ - or $\mathrm{n}$-type with resistivity greater $1 \Omega \mathrm{cm}$. Proceedures were also developed to use small pieces of $\mathrm{Si}$ feedstock in the $\mathrm{mm}$ 
size range, rather than the preferred size of several $\mathrm{cm}$. These measures helped to hold the cost increases in crystal growing due to the Si feedstock shortage to a lower level than they would otherwise have been.

In the wafering area, cost reductions resulted from the implemention of lower-cost wafer cleaning solvent in production, development of improved solvent recovery by distillation, and design and construction of a water-based scrubber for the exhaust from an acetic acid solution. In addition, a reciprocating wire process was developed which drastically reduces the length of wire required per wafer sawn, while potentially improving yields due to reduced wafer taper.

Analysis of the power lost due to resistance in the back screen-printed metallization and comparison to the cost of the back paste led to a reoptimization of the back metallization pattern. The previous back pattern used too little metal paste, and so although paste direct material costs were held low, the power lost in the back metal resistance was high, resulting in a higher cost/watt than necessary. Calculating the optimum grid line spacing, width, and grid line taper options results in significantly lower cost/watt for both 103-mm and 125-mm cells. A back metallization pattern with higher coverage fraction on 125-mm cells was implemented in production in May 1996. Although the amount spent on back metal paste is greater with the new pattern, the module power is greater, translating to a net reduction in module cost/watt.

Working with interconnect ribbon manufacturers led to the use of ribbon formed by rolled wire, which resulted in a $25 \%$ cost reduction for ribbon, and fewer rejects. Negotiations with our glass vendor resulted in a new set of glass specifications which reflect the vendor's process capability, a formalized procedure by which to return defective material, and a $5 \%$ reduction in glass cost.

A new junction box design that features greater versatility for photovoltaic module users and lower cost entered production in May 1996. A schematic of this new junction box, called the PowerMax J-box, is shown in Figure 11. The bypass diodes are pre-assembled in this junction box, allowing logistics savings and increased productivity. The lower cost of this J-box translates to a savings of $0.05 \$ / W$ for present module sizes.

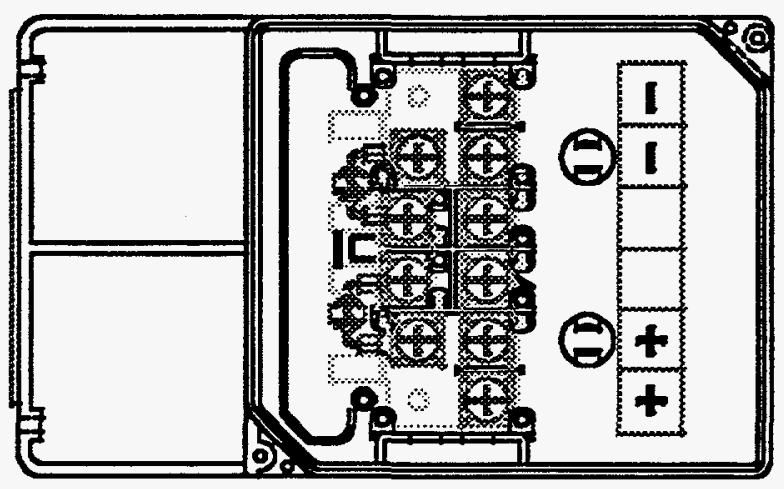

Figure 11. Schematic of PowerMax junction box combining improved flexibility of use and lower cost per module watt. 


\section{Yield and Productivity Improvements}

\section{Types of Yield Loss}

In the discussion of cost in a previous section, yield was found to impact nearly all types of potential cost reductions. Figure 12 plots the relative yield loss for the three process areas of wafering, cell fabrication, and module fabrication. Yield loss in the ingot fabrication area is not included in this chart, since the root causes of yield loss are different after ingot growth, and the focus here is on wafering and the downstream processes. The contribution of ingot yield loss to the overall cost/watt can be seen in Figure 2. Among the three process areas considered in Figure 12, the yield losses for the wafer and cell areas are the highest. However, a given yield loss in the module fabrication area is especially costly due to the high cost per watt at this final point in the process. In Figure 13, the various types of yield loss in the line are plotted. Mechanical breakage is clearly the dominant type of defect causing yield loss. Accordingly, most efforts at improving the yield have been aimed at reducing mechanical breakage.
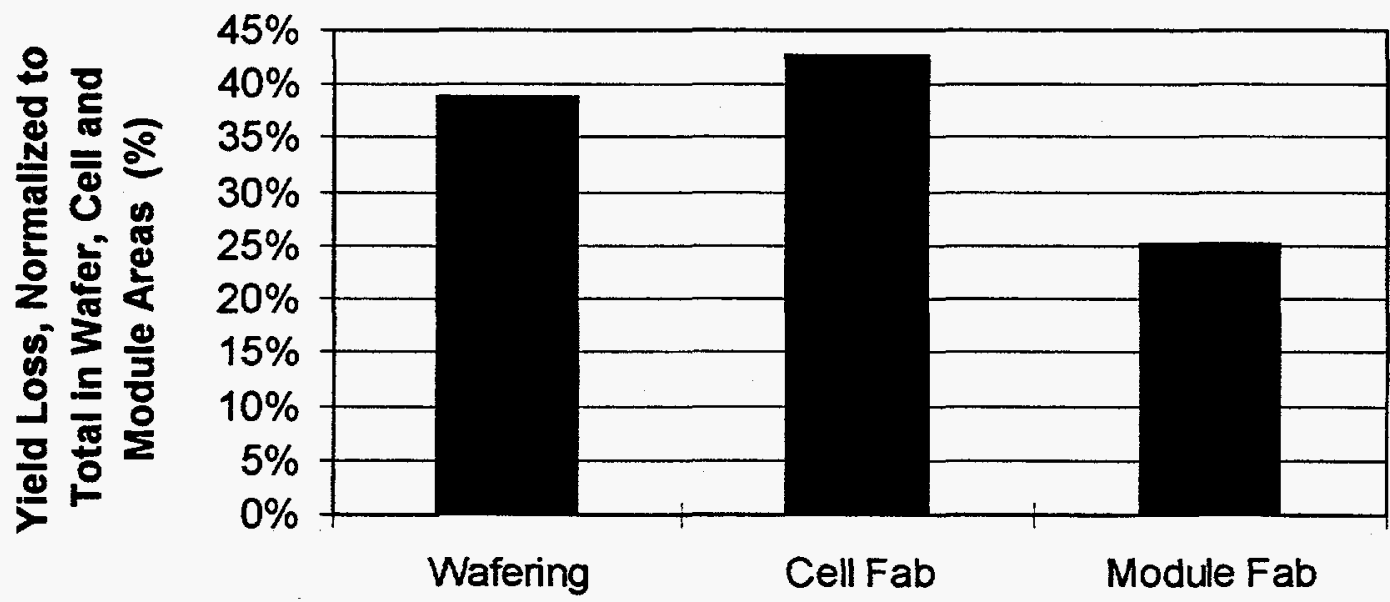

Process Area

Figure 12. Yield loss by process area. Due to the value added at each step in the process, yield loss in the module area is especially costly. 

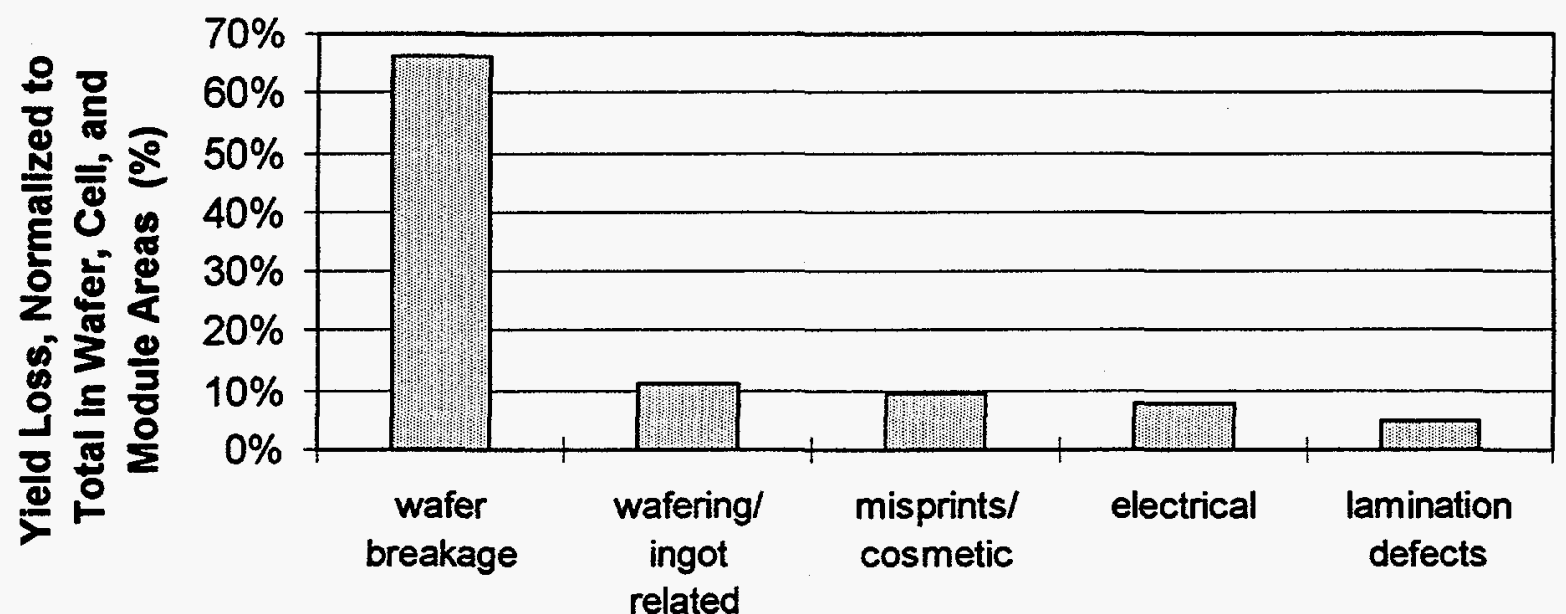

Type of Yield Loss in Wafering, Cell Fab, and Module Fab Areas

Figure 13. Yield loss by type of defect. Wafer breakage is by far the dominant loss mechanism for the wafering, cell fabrication, and module fabrication areas.

\section{Breakage Force Studies}

In order to provide more information about the root causes of wafer breakage, the average breakage force of wafers was measured by a stylus lowered at a controlled rate in the center of the wafer resting on two horizontal rails. The force required to break wafers in this configuration was measured for multicrystalline$\mathrm{Si}$ (mc-Si) wafers and for single-crystal SSI $\mathrm{Cz}$ wafers, at 6 different points in the cell fabrication sequence, from as-sawn wafers to finished cells. Although standard SSI Si solar cells are single-crystal Cz, mc-Si wafers were evaluated for comparison. The data is shown in Figure 14. Each bar represents the average of breakage force measurements on 25 wafers, except for after Step 4, where the data set was only 10 wafers. The error bars indicate \pm one standard deviation. These breakage force measurements may not highlight precisely the same mechanisms that cause breakage in the manufacturing line, but do provide a relative measure of wafer strength that can indicate major effects of wafer processing, and of different silicon materials.

Throughout the cell process, the breakage force of mc-Si is fairly similar to that of single-crystal SSI Cz. As sawn, the wafers are 50-60\% weaker than after texture etching (after Step 1), and the mode of breakage is qualitatively different for the single-crystal $\mathrm{Cz}$. Before etching, the $\mathrm{Cz}$ wafers tend to cleave into quarters, while after etching the wafer shatters into a larger number of small pieces. One explanation is that microfractures or other irregularities on the as-sawn wafer surface can serve as nucleation sites for larger fractures when the wafer is stressed during the breakage force measurement. The fracture nucleation sites on the as-sawn wafer are likely to be removed or their density decreased by the wet etching solutions.

For most of the cell process after etching, the breakage force stays fairly constant within the experimental uncertainty. On printed and fired cells (after Steps 5-8), however, the average breakage force drops by $\sim 35 \%$ for both types of material. This could be due to the surface imperfections caused by the metal contacts. It is interesting to note that for all of the process steps after wet etching, the standard deviation of the breakage force measurements was higher for the mc-Si wafers than for single-crystal SSI Cz, perhaps due to the variation in crystal orientation in $\mathrm{mc}-\mathrm{Si}$. 


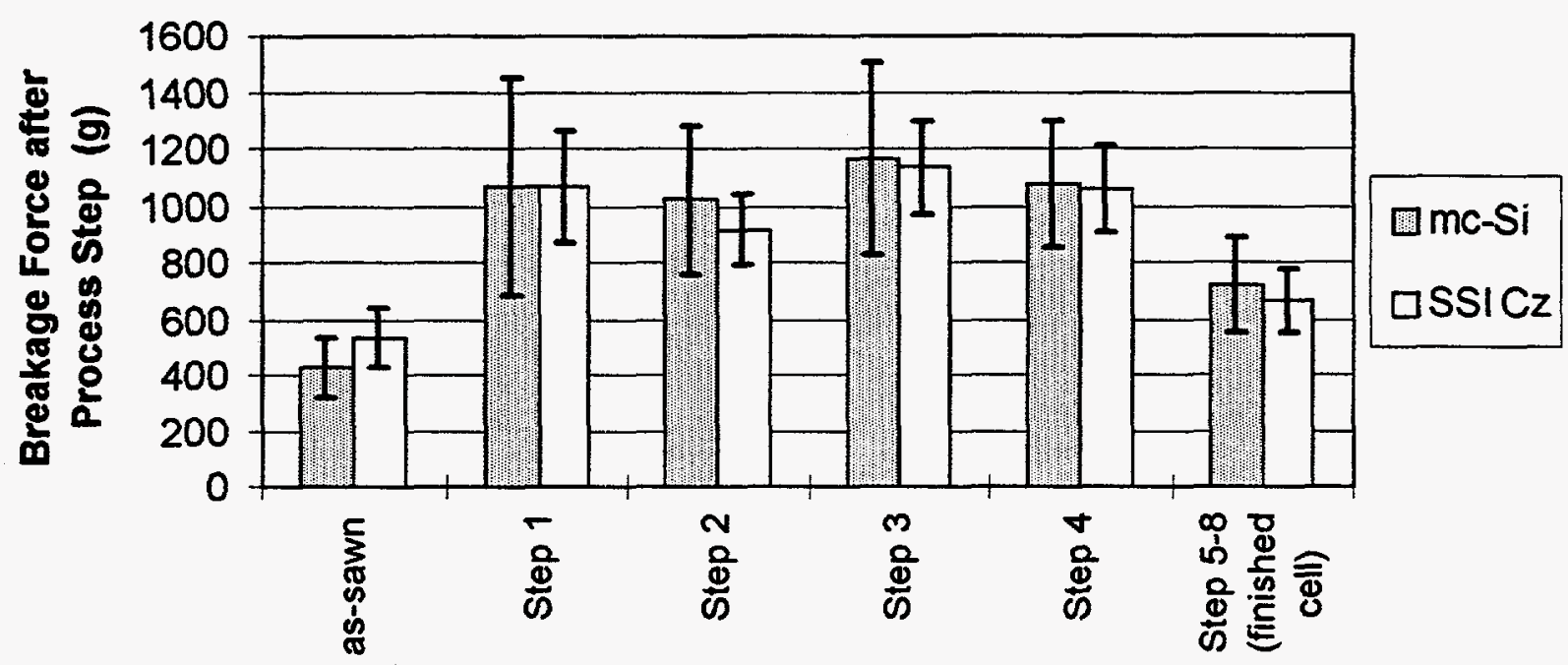

Process Step (from as-sawn to finished cell)

Figure 14. Wafer breakage force of multicrystalline-Si (mc-Si) and SSI CZ Si, as measured by a stylus for wafers resting on two horizontal rails. The error bars indicate \pm 1 standard deviation in the data.

\section{Mechanical Yield Experiments}

The mechanical yield and electrical performance of multicrystalline-Si (mc-Si) substrates through the SSI cell fabrication line were also measured in order to evaluate the use of mc-Si wafers in addition to or instead of the single-crystal $\mathrm{Cz}$ Si normally used at SSI. Multicrystalline-Si ingots from two vendors (A and B) were wire sawn at SSI. A standard format for tracking mechanical yield was developed, in which the wafer breakage is recorded at 43 steps in the cell process to identify problem areas, for both the type of wafer under test and for standard SSI $\mathrm{Cz}$ Si processed at the same time. The number of wafers in each group is $\mathbf{8 7 5}$ at the start of cell processing.

Figure 15 shows the mechanical yield for mc-Si from Vendor $\mathrm{A}$, lumped into 8 major process areas from as-sawn wafers to finished cells. The overall mechanical yield through SSI cell processing in this experiment was $92.0 \%$ for the mc-Si, compared to $99.0 \%$ for standard $103-\mathrm{mm} \mathrm{SSI} \mathrm{Cz}$ wafers. The low yield for mc-Si in this run is attributable in part to an improper fit of the square mc-Si wafers in the wafer carriers in diffusion, as noted for Step 2 in Figure 15. For Steps 4, 6, and 7, the mechanical yields were somewhat lower than for SSI Cz. Factors contributing to this lower yield could be damage at the corners of the mc-Si from contacting the wafer carriers in diffusion, the square shape of the wafers causing problems at other wafer handling steps, or an intrinsic difference in the susceptibility of this type of mc-Si to breakage in the SSI line compared to SSI Cz. 


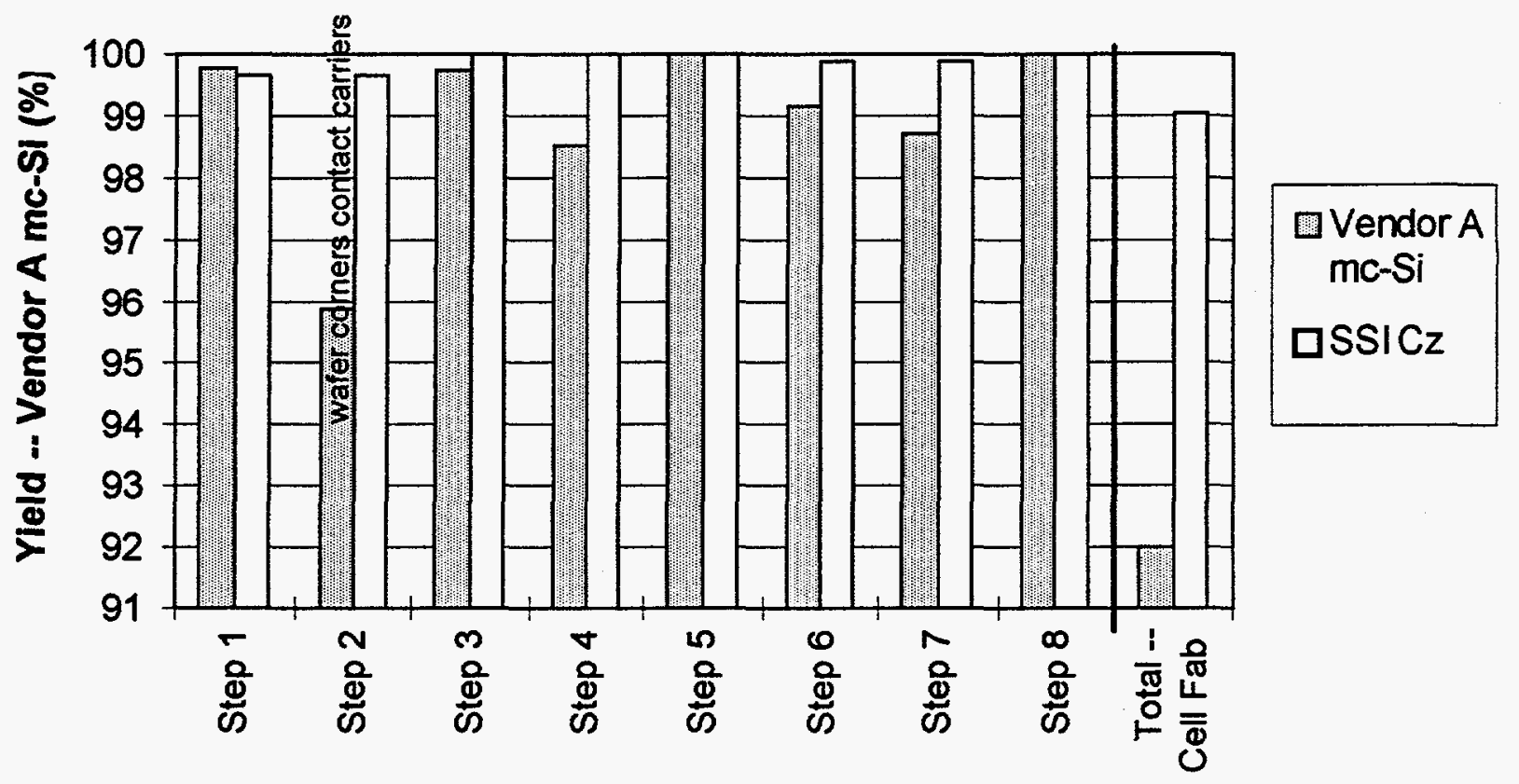

Process Step (from as-sawn to finished cell)

Figure 15. Mechanical yield of multicrystalline-Si (mc-Si) afers from Vendor A, in SSI cell fabrication process.

These mc-Si cells from Vendor A ingot were assembled into strings for module fabrication on an automatic soldering machine, and the yield was tracked in a similar way. Mechanical yield was $99.8 \%$ for the mc-Si and $99.3 \%$ for SSI Cz. For the SSI Cz, all breakage occured during the thermal and mechanical stress at the time of soldering, while for the $\mathrm{mc}-\mathrm{Si}$, no breakage occured during the actual soldering.

The mechanical yield of mc-Si from another vendor (Vendor B) was also tracked through SSI processing in the same way, as shown in Figure 16. The largest difference between mc-Si from vendor $\mathrm{B}$ and SSI $\mathrm{Cz}$ was in back printing and firing area (Step 7), with breakage of $1.3 \%$ for the mc-Si and $0.0 \%$ for standard SSI Cz. Breakage in Step 2 was lower for the mc-Si than for SSI Cz. New wafer carriers designed to clear the square corners of the mc-Si wafers were used in this run. Overall mechanical yield for the cell fabrication process at SSI was $96.7 \%$ for mc-Si from Vendor B and $98.2 \%$ for SSI Cz in this test. 


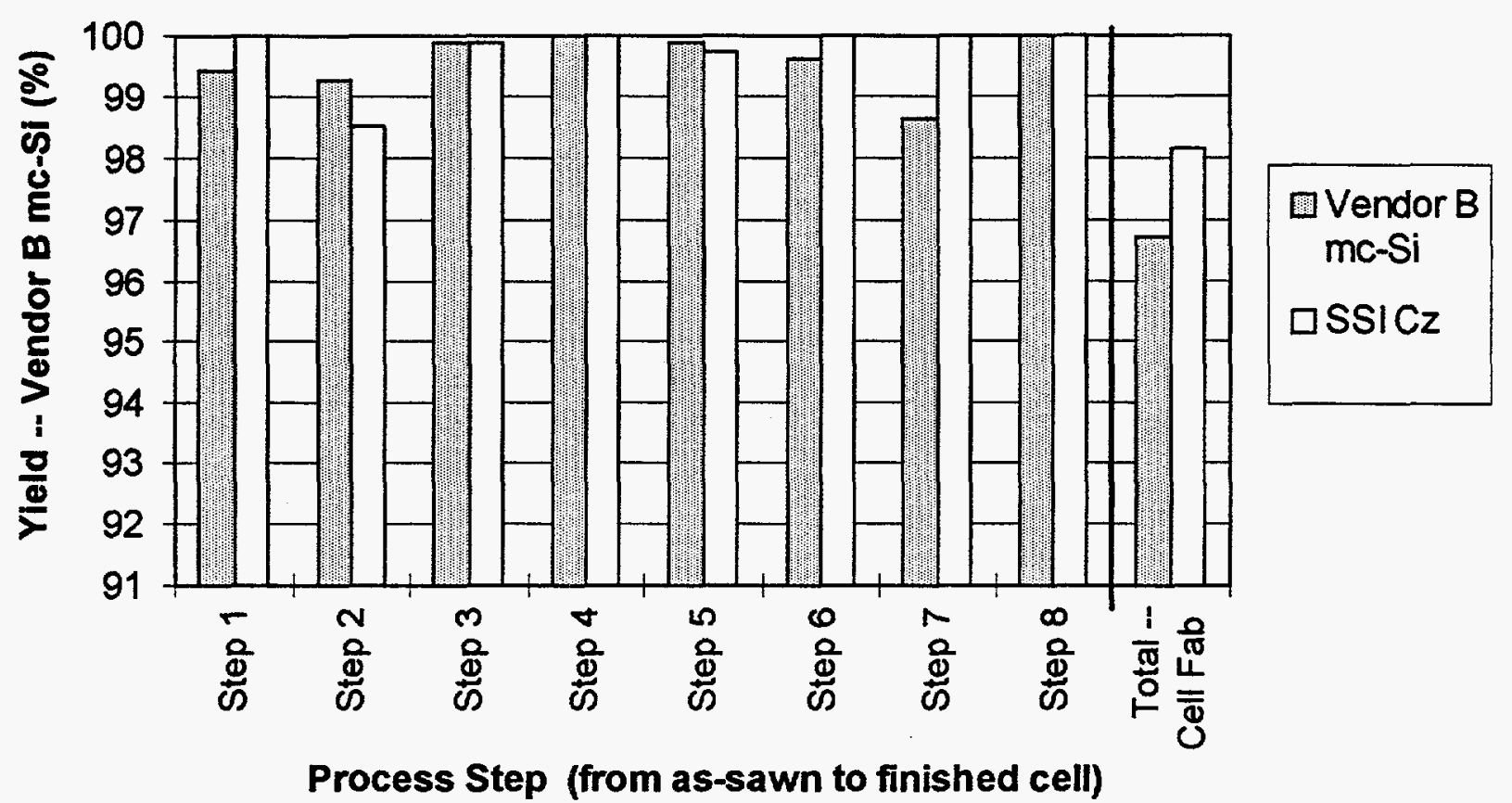

Figure 16. Mechanical yield of multicrystalline-Si (mc-Si) wafers from Vendor B, in SSI cell fabrication process.

Figure 17 shows the cell electrical distribution for mc-Si from Vendors A and B, and for SSI Cz in these experiments. The cells are binned according to $\mathrm{I}_{\mathrm{vr}}$, defined to be the cell current at a rated voltage of 0.484 V. The cell performance for both mc-Si materials is similar, with an electrical distribution much lower than that of the single-crystal $\mathrm{Cz}$ substrates. The SSI cell process is not optimized for $\mathrm{mc}-\mathrm{Si}$, so it is possible that this electrical performance could be improved by tuning some of the fabrication processes for mc-Si. Figure 18 shows the cell performance of the mc-Si relative to SSI $\mathrm{Cz}$, broken down into the electrical parameters $\mathrm{V}_{\mathrm{oc}}, \mathrm{I}_{\mathrm{sc}}$, and $\mathrm{FF}$, and the combination of these in the cell efficiency. The mc-Si shows low $I_{s c}$ values of $83-85 \%$ that of the SSI Cz, uncorrected for the larger area of the mc-Si cells (both $\mathrm{mc}-\mathrm{Si}$ and SSI Cz were $103 \times 103 \mathrm{~mm}$ substrates, but the SSI Cz wafers have rounded corners). Part of the current loss on mc-Si relative to $\mathrm{SSI} C z$ results from the incomplete texturing on $\mathrm{mc}-\mathrm{Si}$, due to the random grain orientation, and part from the lower bulk lifetimes typically seen in mc-Si substrates. The mc-Si $\mathrm{V}_{\infty}$ was $95-98 \%$ that of SSI $\mathrm{Cz}$, and the FF was $96-99 \%$ of the average value for $\mathrm{SSI} C z$, resulting in cell efficiency of $77-80 \%$ that of the SSI Cz for the mc-Si evaluated in this experiment. 


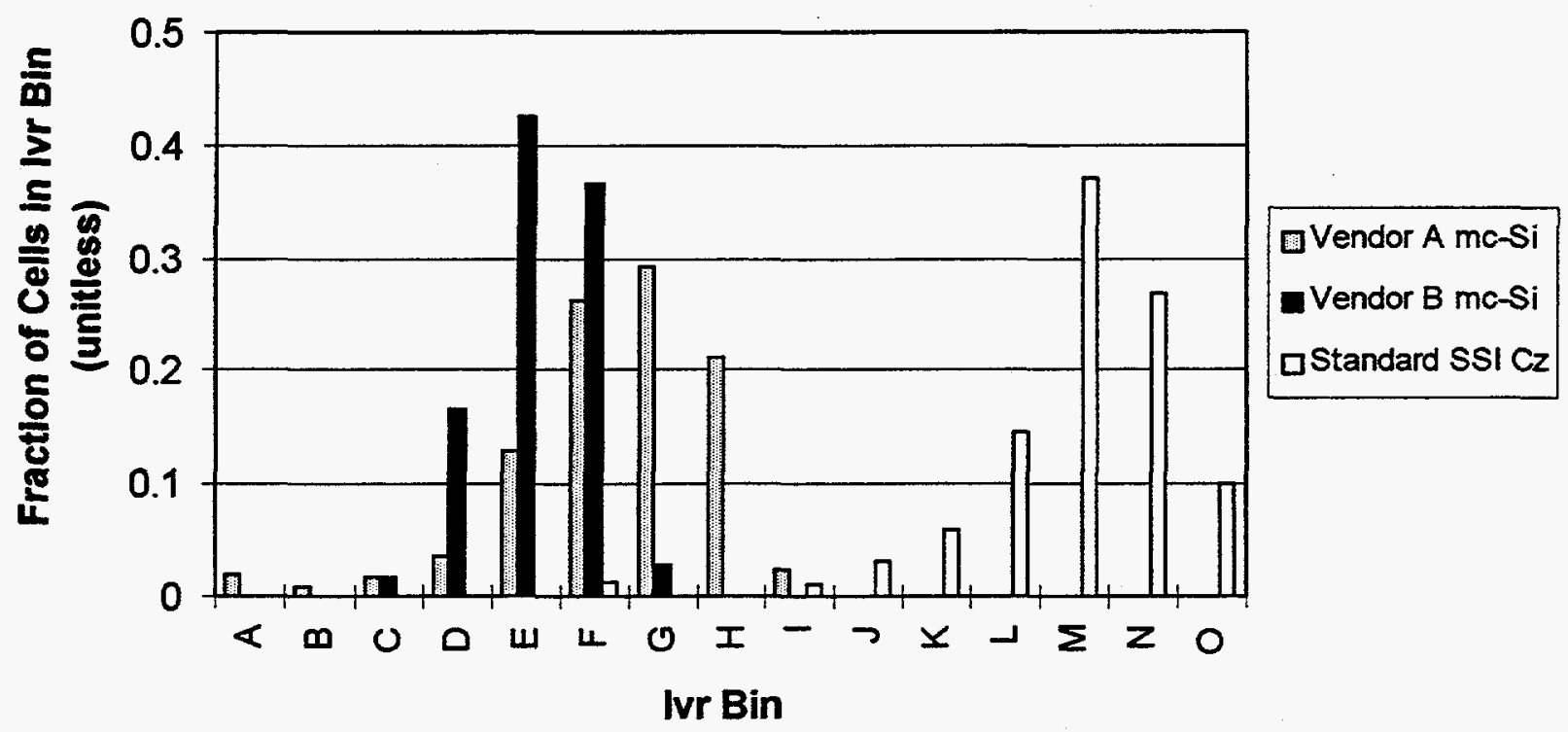

Figure 17. Electrical distribution for SSI Cz and mc-Si substrates. $I_{\mathrm{vr}}$ is the cell current at a rated voltage of $0.484 \mathrm{~V}$, and is proportional to the cell power at that fixed voltage.

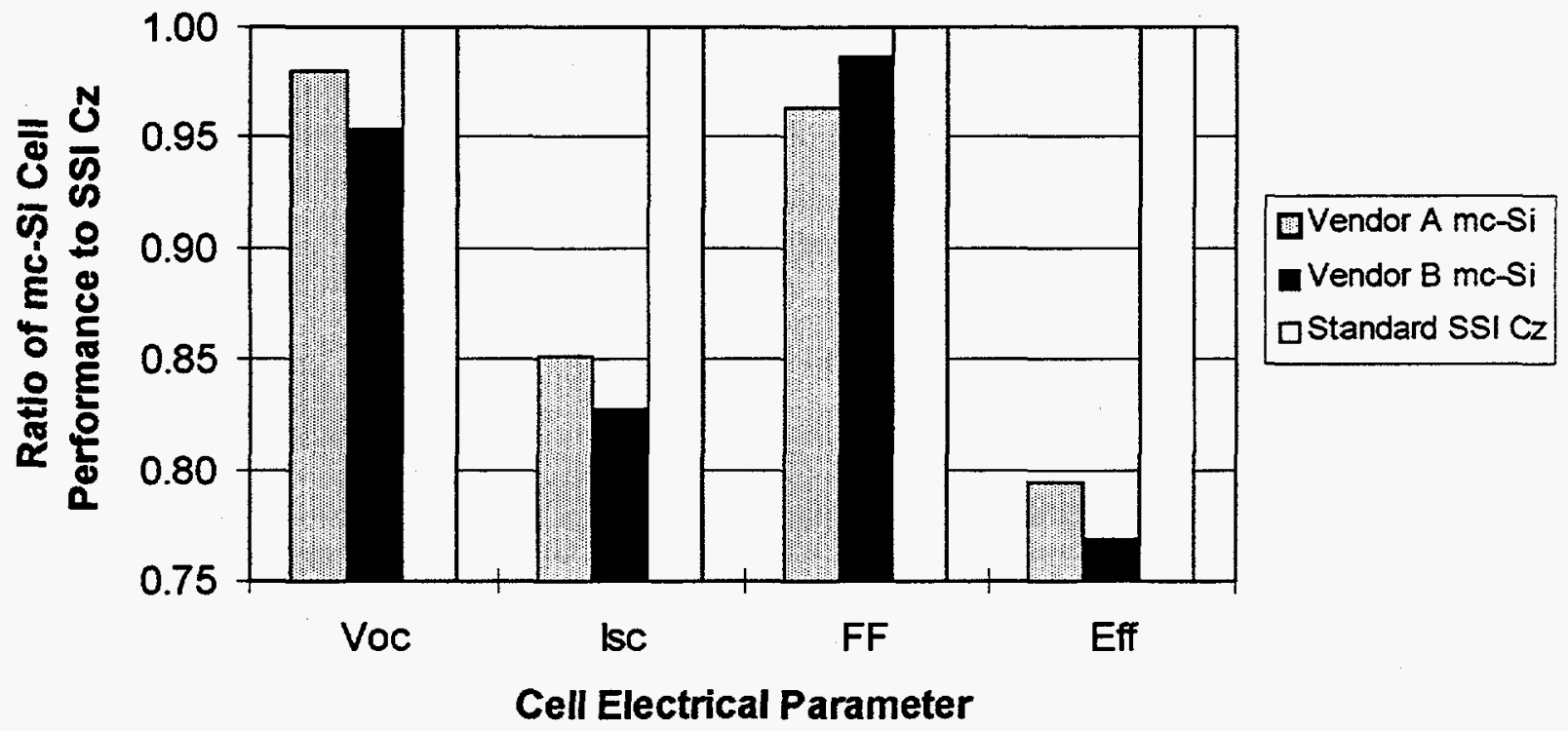

Figure 18. Comparison of cell electrical parameters for multicrystalline-Si and SSI Cz. 
Another experiment to measure mechanical yield in the SSI cell fabrication line was conducted on wafers with and without linear features on the surface that can be caused by wire sawing (called wire lines). Irregularities on the wafer surface can lead to stress concentration and initiation of a fracture in the wafer, so one possibility addressed by the experiment is that the wafers with wire lines may be more prone to breakage in subsequent fabrication processes than the wafers without wire lines. For the cell fabrication process, the overall breakage rate was $0.9 \%$ (absolute) higher for the wafers with linear wire saw features on the surface. This would seem to support the above hypothesis, but confirmation runs would need to be made to draw the connection with certainty. At present the wafering process is such that the wafers without wire lines are much harder to separate immediately after sawing than are those with wire lines. As a result, the wafers without wire lines experienced a $0.7 \%$ (absolute) higher breakage rate during this step prior to the beginning of the cell fabrication sequence, effectively negating the lower breakage in cell fabrication. With modification to the wafering process to facilitate wafer separation, the reduced tendency of wafers without wire lines to break in the cell process steps could be utilized.

Some of the wafer breakage that occurs in cell fabrication is due to preexisting wafer or ingot defects, such as small chips on the wafer edge, or hairline fracture due to stress in the silicon ingot. To better understand the role of these mechanical defects in cell yield, the incidence of wafer defects was determined at several points in the cell fabrication sequence, during a short time frame. Populations of wafers consisting of wafers which all have the same type of defect, or of wafers with no defects, were run through the process to observe the effect on mechanical yield. Several key findings were:

- Wafers with edge chips that do not extend all the way through the wafer (known as clamshell chips from their appearance) broke at a rate of $3.1 \%$ through the wet etching steps in this experiment, as opposed to $0.3 \%$ for defect-free wafers (wafers with no edge damage or pre-existing fracture). Imperfections on the wafer edge or surface can act as nucleation sites for fracture.

- During the short time frame of the sampling, $1.9 \%$ of wafers entering the wet etching steps have edge chips that do extend through the wafer (known as regular chips), an even more serious defect than the clamshell chips above. These wafers with regular chips are removed from the cell process and therefore are as detrimental to cell yield as a broken wafer.

- Immediately prior to diffusion, $0.6 \%$ of the wafers in the sample taken have a partial fracture extending only part of the way across the wafer. This defect is likely to occur in crystal growing or ingot shaping, since the fracture is often found the same location on consecutive wafers. Such wafers usually break during the boating process right after wire sawing, but some last through the wet etching steps. Wafers with partial fracture are almost certain to break before reaching the end of the cell process.

- Wafers with clamshell chips do not have a much higher breakage rate than defect-free wafers in the diffusion and oxidation processes, indicating that pre-existing clamshell chip defects are not the main cause of breakage in this area.

- Breakage in the diffusion and oxidation processes was $0.2 \%$ for a group that included wafers with and without defects, suggesting that thermal processes do not have as much effect on yield as do wafer handling steps in the area.

- Defect-free wafers broke at a rate of $0.7 \%$ through the part of the cell fabrication process that includes printing, contact firing, and testing. 
Both regular and clamshell chips were observed to be most prevalent on the edge of the wafer that was bonded with epoxy during wafering, and at the corner between the flat and rounded regions of the perimeter. The 150-mm round wafers under development will have fewer such comers, with a much more oblique angle, and so may have less breakage due to corner chips.

\section{Specific Measures to Increase Yield}

\section{Wafering}

Understanding of the factors which influence yield in wire sawing has increased considerably in Phase $I$. Sources of yield loss in wire sawing include: wire ruptures, ingot debonding from its support beam, out-ofspec average wafer thickness, excessive thickness variation across a wafer, chip formation on the wafer edge, wafer surface contamination, and, of course, wafer breakage after sawing.

A important capability for feedback to the wire saw process is rapid, accurate, multi-point measurement of thickness across a statistically significant number of wafers from each wire saw run. A new personalcomputer-based wafer thickness gauge was introduced in the wafering area. Previously, after wafering an ingot, 25 wafers were selected from various positions throughout the ingot, and the thickness was measured with a manual gauge at five points on each of these wafers. The thickness values were typed individually into a spreadsheet program for data analysis. The new thickness gauge uses a capacitive method to measure thickness on five or more points across each wafer at once, and the data is automatically downloaded to a spreadsheet file. Wafer bow data can also be gathered with this instrument. The distribution of thickness values made with the manual gauge is not smooth and shows spikes in the data, presumably due to variation introduced by the operator. In contrast, the data from the automatic measurement system forms a smooth, gaussian distribution. The automatic data also showed a mean thickness that was $10 \mu \mathrm{m}$ lower than the average of the manual measurments, possibly due to the broad platform for the wafer on the manual gauge, allowing wafer bow to influence the thickness measurement. A discrepancy of $10 \mu \mathrm{m}$ in thickness is important to understand, as it impacts wafer strength and breakage through the rest of the process.

The rapidity of the thickness measurement is crucial in order to provide timely feedback to the wire saw operators. Based on the thickness measurements on a sample of wafers from each wire saw run, the probability of incidence of out-of-spec wafers, in terms of either average wafer thickness or thickness variation across the wafer, is calculated and available to the wire saw operator before beginning the next run. This allows the operator to be alerted to non-optimum conditions, and check saw parameters such as wire tension, change cutting slurry, or make other checks to correct the problem.

Feedback on the overall yield of each wire saw run due to all sources of loss, such as wafer breakage, wire rupture, chips, double-thickness wafers, etc. is also important for wire saw operators and engineers to make informed decisions. The parts-per-million loss due to each of these causes is quantified and charted for consecutive runs on each wire saw. The updated charts for each machine are posted daily in the wafering area, to quickly identify problem saws and detect trends in the yields.

A large source of process variation was traced to the silicon carbide abrasive obtained from various vendors for use in the cutting slurry. Analysis of the $\mathrm{SiC}$ particles indicates that the shape of the grains influences the uniformity and repoducibility of the wafer thickness. Significant increases in wafering yield were achieved by reducing the variability in the $\mathrm{SiC}$ particles associated with one of the vendors. 
The epoxy used for mounting the ingots on a support beam was found to stress the ingots, if mixed improperly, resulting in increased wafer breakage. The previous blend of the two-part epoxy had excessive shrinkage, and stressed the ingot more than necessary. Adjusting the blend to result in less shrinkage and therefore less stress can result in long cure times, or in extreme cases, debonding of the ingot from the support beam. An optimum blend was found which has acceptable cure times, holds the ingot securely during cutting, and yet does not subject the ingot to excessive stress, resulting in reduced wafer breakage. Bead blasting of the support beam was also developed to improve adhesion to the epoxy.

A critical step in wafer fabrication, which is often overlooked, is the cleaning of wafers after sawing. Failure to remove the cutting slurry residues after sawing can cause contamination of the downstream processes, visible surface nonuniformities on the wafer surface, and lower cell electrical output. A new automated wafer cleaning line was developed and installed in Phase I. In combination with the previous wafer cleaning line, the new cleaning machine can increase either the capacity or the thoroughness of the wafer cleaning process. Increasing the capacity of this step can be vital for maintaining high yield, because the slurry becomes extremely difficult to remove with any cleaning step if the wafers are allowed to sit in air for an extended period of time before cleaning. If the cleaning step is a bottleneck, then wafers can build up after boating before they can be cleaned. Another measure implemented to combat this problem is that a maximum of 10 wafer boats are allowed to be waiting after boating and before cleaning. A new method for removing the epoxy strips from the bottom of wafers was also developed and implemented in the automatic wafer cleaning line, resulting in fewer chips on the wafer edge.

\section{Cell Fabrication}

When the cell fabrication process steps at which wafer breakage occurs are categorized in terms of 1) machine handling, 2) operator handling, 3) thermal processes, and 4) other, most wafer breakage occurs during operator handling steps. This finding, in addition to the observation that wafers could be handled with greater deliberation and care at some steps, led us to address the issue of operator handling directly. Charts were posted in a prominent location and operators were trained to collect and plot the wafer breakage data at the end of each shift. This has heightened the operators' awareness of the magnitude of wafer breakage in the targeted area of cell fab process steps $1-4$, and the effect that they can have on it. By having a frequent feedback mechanism by which the operators can gauge the effect of their efforts to handle wafers more carefully, they have achieved a significant increase in the average mechanical yield. The shift in the average breakage rate that occured in September 1996 when this feedback mechanism was strengthened is shown in Figure 19. The variation in breakage rate has also been tightened, as shown by the decrease in the upper control limit starting in September. 


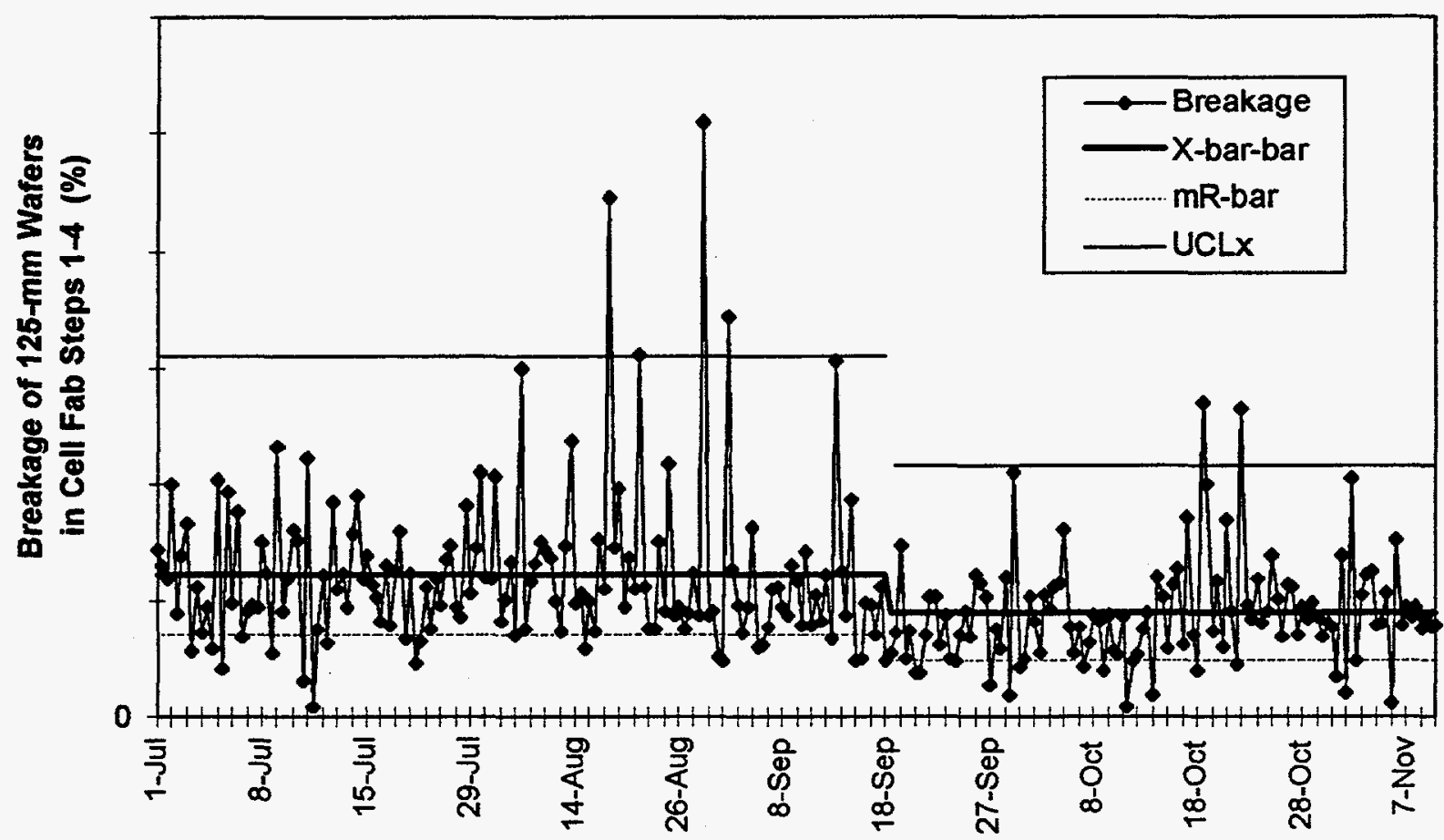

Figure 19. SPC chart of $125-\mathrm{mm}$ wafer breakage in the first four process steps in cell fabrication. The downward jog in average breakage and range coincides with greater operator awareness of the breakage yield problem and greater visibility of the data, as described in the text.

Wafer edge chips constitute a serious type of defect that impacts the mechanical yield in cell fabrication. As discussed above, edge chips are grouped into two classifications: regular chips, which extend through the entire wafer, and; clamshell chips, which do not extend all the way through the wafer. Procedures and work instructions were established to eliminate regular chips at various points in the line, and treat them as a scrapped wafer, the way a broken wafer would be treated. Regular chips are eliminated from the product flow before the 2nd half of cell fabrication, which includes AR coating, front and back printing, contact firing, and cell testing. They are inspected for and removed again before the automatic cell soldering process.

Taking this yield loss early in the cell process has several benefits for yield:

1) A wafer with an edge chip that extends through the wafer is unlikely to make it through the rest of the cell fabrication, soldering, and lamination processes without cracking. This being the case, it is better to be rid of the wafer before more materials and labor are added to the cell, and even more importantly, before the cell has a chance to crack in a laminate, thus causing $~ 35$ good cells to be scrapped along with it.

2) When a relatively large percentage of cells are breaking in automatic wafer handling equipment, such as the automatic soldering equipment and the multitude of wafer loaders and unloaders in the 2 nd half of cell fabrication, broken pieces of wafer can cause an avalanche effect, causing the next, defect-free wafers coming through the machine to jam and break also. The productivity of the operators and of the equipment is also severely impacted, because of the need to frequently stop the process to clear the machine of broken wafers. 
3) A more subtle effect of a high breakage rate through a piece of process equipment is that operators become acclimatized to poor yield conditions, treating it as the normal course of events. They are then less likely to investigate the root cause of the yield loss and take the steps neccessary to correct yield loss problems, even ones that can be easily remedied.

4) Eliminating regular chips before one process segment clearly allows one to determine how many chips come from upstream processes, and how many chips are generated in the process segment in question. The 2nd half of cell fabrication has numerous wafer stops used to align the cells for loading, unloading, printing, and testing equipment, which can cause edge chips themselves. When the rate of chip generation is made visible, steps can be taken to isolate the machine causing the chips, and realign it or find other means to fix the problem.

For these reasons, inspection and removal of regular chips before the 2 nd half of cell fabrication and before automatic soldering has had a dramatic effect on the yield in those two process segments.

A machine vision system for inspecting wafers both before and after front contact printing was developed and installed. Before front print, the vision system can detect wafers with out-of-spec dimensions, such as a comer-to-comer diameter that is too small. Such wafers can cause metal to be printed on the edge of the wafer or on the metal cell chuck, causing yield loss. After front print the system can detect a wide variety of print defects, such as grid line voids, tears in the print screen, double prints, and misaligned prints. Having a machine perform this inspection is valuable for at least three reasons:

1) Immediate feedback on print defects is essential to catch the problem before many parts are ruined with a rejectable defect. The equipment configuration is such that it is difficult for the print operator to see a print problem until many wafers have gone through the printer.

2) Inspection by an operator is far from $100 \%$ accurate, due to fatigue, inattention, interpretation of reject criteria, etc. This allows the possibility that some rejectable cells would not be scrapped as they should be, and that conditions such as a screen tear could persist for many printing cycles, causing many cells to be scrapped needlessly.

3) Productivity of the print operator can be increased, since the vision system frees him or her to attend to the tasks associated with running the line other than inspection, to fill in for other operators absent or on breaks, etc.

A key process control point in the cell process is the contact sintering (firing) process after front and back screen printing. This is a dynamic process, which can cause the cell fill factor (FF) to vary from nearly zero up to its maximum values above $75 \%$, through the strong dependence on firing time and temperature profiles. The definitive test of firing condition optimization is the cell fill factor that results. This is the method used in manufacturing to find the best firing temperature. Although this is a direct optimization method, it has a fairly long feedback time of 15 minutes or so, and requires some effort on the part of the operator. Because many factors can influence the optimum firing conditions, such as wafer thickness, furnace loading, ambient air temperature, lamp age, etc., the frequency of this firing temperature tuning was increased, and the data from sequential FF checks posted, resulting in tighter control over this key electrical parameter.

A problem area for wafer breakage during automatic wafer handling is at the station for unloading wafers from the contact firing furnace belt. Vibration of the belt tends to misalign wafers so that they do not descend smoothly down the lanes designed for unloading. Design and experimentation with adjustable lane 
guides, increased air jet pressure for low-friction transport down the unloader lanes, and measures to reduce belt vibration have resulted in far less wafer jamming and breakage at this point. Operator productivity is also significantly improved, due to fewer events in which the back print operation must be left to fix a wafer jam in the belt unloader.

\section{Module Fabrication}

The foundation of yield improvements in the soldering area is development of accurate tracking and recording of breakage on the automatic cell soldering machines. This is the gauge by which the dependence of a process change on the yield can be measured under actual production conditions. Work instructions formalizing the methods for gathering and posting this data were completed in Phase I of this contract. An example of this yield chart is shown in the section on SPC, in Figure 21. Elimination of chipped wafers prior to soldering had a dramatic effect on yield in this step, through the reasons described above, such as fewer broken pieces in the machine that can break subsequent wafers, easier isolation of the root causes of the edge chips, etc. SPC charting of the yield in various parts of the machine show that the breakage in the lamp-heated zone, in which the cells are subjected to both thermal stress from non-uniform, rapidly changing temperatures, and mechanical stress from the rollers which hold the ribbons, is much greater than in the automatic wafer handling part of the system, in which the cells are picked from a stack and flipped in order to apply solder paste on front and back.

It was also found that the soldering machine yields are strongly dependent on machine setup parameters, such as alignments, roller pressure, lamp power, etc. A detailed troubleshooting list was developed, giving the operator a way to rectify many simple problems on the machines, without the delays and productivity loss associated with waiting for a maintenance technician. The SPC charting of yield provides the operator with an unambiguous way to tell that the machine is causing poor yield; the list of specific action plans for many commonly encountered yield problems offers a way to fix it. Operator training is an essential part of this approach, both to explain the technical aspects of setup and troubleshooting, and to build operator awareness of and greater responsibility for yield.

Finally, yield experiments and confirmation runs showed that the greater yield obtained with thicker 125mm substrates (nominally $400 \mu \mathrm{m}$ as opposed to the previous $325-\mu \mathrm{m}$ thickness) outweighs the fewer number of the thicker wafers that can be cut from a given length of ingot. Standard production 125-mm wafers were switched to the greater thickness in Phase I, resulting in reduced breakage in wafering, cell fabrication, and soldering. 103-mm wafers did not show as strong an advantage for increased thickness, and so standard 103-mm wafers remained at the thinner $325 \mu \mathrm{m}$. With improvements to the wafer handling systems throughout the line, it is anticipated that wafer thickness can be reduced while maintaining high yield, but in the present manufacturing environment these thicknesses are close to optimum.

\section{Overall Yield Improvement in Wafering, Cell, and Module Areas}

Due to the improvements in yield described above, among others, the line yield in the wafering, cell fabrication, and module fabrication areas combined increased by 8.5 relative \% from the period of Oct. 1994-Sep. 1995 (fiscal year 1995), to the period of Oct. 1995-Sep. 1996 (fiscal year 1996). The latter period corresponds to within about a month with Phase I of this project. So the goal of $5 \%$ or greater increase in yield in Phase I has been met for these three process areas considered together. The yield in ingot fabrication is not considered here, due to the special circumstances brought about by the silicon feedstock shortage in this time frame. The unavailability of traditional feedstock materials forced the use of many alternative types of feedstock, most of which caused far lower yield in crystal growing than the 
previous materials. We are learning how to treat these new feedstocks to increase yields above their initial values, but the silicon feedstock shortage remains a serious problem for crystal growing yields.

\section{Specific Measures to Increase Productivity}

Productivity is a measure of the ability to manufacture finished goods with a given pool of employee labor, and is defined here as the number of kilowatts produced at the module level divided by the number of manufacturing employees. Unless otherwise specified, only direct labor employees are used to calculate productivity. As described in the introduction, methods to increase productivity at SSI during Phase I fall into four categories: 1) automation; 2) preassembled parts or preinspected materials; 3) reevaluation of staffing requirements; and 4) improved material supply logistics.

Automation clearly has the capability to reduce operator labor, and in some cases can benefit yield simultaneously. The automatic wafer cleaning line described earlier, in addition to providing greater cleaning capacity, requires fewer operators to run and thus increases productivity. The vision system at front printing improves productivity by freeing the print operator from the task of $100 \%$ inspection of incoming and outgoing parts, and reduces the incidence of misprints at the same time. Another vision system for automatic counting of cells in stacks after electrical test was also developed, allowing far less labor to be spent on the task of cell counting before packaging.

Vendors of components for photovoltaics manufacture can often perform inspections or simple assembly steps at their site on the parts they provide more efficiently than it can be done in the PV manufacturing facility. Agreements were made between SSI and silicon feedstock suppliers to presort silicon batches by their resistivity, saving the labor at SSI that would otherwise be required to check the resistivity and type of each piece of incoming silicon. Often, the resistivity is already known by the supplier, so in this case it is simply a matter of retaining the information through the sale. Agreements established with our glass vendor reduced reject rates for glass defects, and streamlined procdures for effecting the return when defects do occur, also resulting in increased productivity. The new junction box with preassembled bypass diodes described earlier reduces both assembly and receiving inspection labor.

Cross-training of operators in the 2 nd half of cell fabrication has helped to avoid redundancy in staffing in this process area. Operator breaks and unplanned absences are a normal part of any manufacturing endeavor. If each operator is trained to run multiple pieces of manufacturing equipment, then the work force is much more flexible and can adapt to short periods of time in which fewer operators than normal are available. Cross-training also has the benefit of giving the operators a broader perspective on the overall process and more variety in their work. Staffing level in the soldering area was found to be neutral with respect to yield, as long as the core functions were attended to. In this case, since there was no effect of the number of employees on yield, the lower soldering staffing level, which offers higher productivity, could be chosen.

Several rework loops in SSI PV manufacturing have been removed, as part of a general policy to eliminate rework whereever possible, even if the short-term effect on yield appears negative. This has several benefits. First, processing material through the same step twice is clearly a drain on productivity and should be avoided. Second, scrapping the parts draws a great deal of attention to the defect in question, which is a necessary first step to correct the root cause of the problem. Third, reworked parts are usually not as high in quality as material processed correctly the first time through.

Consolidating crystal growth operations into the single Vancouver, WA site improved productivity in addition to reducing costs, through the elimination of redundant support facilities. Inventories for grower 
parts were reduced and the logistics for supplying those parts were simplified, by standardization of the components used in different grower models in Vancouver.

New procedures were also developed for joining short ingot sections by epoxy in Vancouver to form a suitable length for the wafering process. Because the sections are joined before the ingot shaping steps, far fewer setup operations need to be done on the ingot shaping equipment, and the machine programs can be standardized for a constant length. Previously, when the ingot section joining was done in Camarillo, appropriate section lengths were often not available to form the desired joined ingot length for wire sawing. A much wider assortment of ingot section lengths are available in Vancouver next to the crystal growth operations, facilitating the job of matching sections. These advantages all boost productivity. Yield in crystal growing is also enhanced somewhat, since shorter ingot sections can now be used.

\section{Overall Productivity Improvement}

Again comparing the periods of Oct. 1994-Sep. 1995 (FY 1995) and Oct. 1995-Sep. 1996 (FY 1996), the overall productivity in the SSI photovoltaic manufacturing process increased by $6.5 \%$ for direct labor. So the goal of a $5 \%$ or greater rise in productivity in Phase $I$ of this project has been met. The productivity is calculated in terms of the number of $\mathrm{kW}$ produced at the module level divided by the number of direct labor employees. Since a large fraction of the photovoltaics output of SSI is in cell sales, rather than module sales, the number of employees in the module area was increased in the productivity calculation to account for the greater number of module fabrication employees that would be required if all cells made at SSI were processed into modules. Thus the productivity values assume zero cell sales and all plant output is in the form of modules. If indirect manufacturing labor is also included in the calculation, the productivity was boosted even more, by $11.8 \%$ between the same two time periods. 


\section{Manufacturing Systems to Improve Module Reliability}

\section{ISO 9001 Certification}

The SSI Camarillo plant received ISO 9001 certification in March 1996. This is a major milestone in the pursuit of quality manufacturing systems, and represents a very substantial effort by the company to establish and document procedures, operator work instructions, maintenance and calibration schedules, conduct operator training, etc. The benefit is a profoundly improved system to ensure manufacturing compliance and control of its processes. It is, however, only a beginning.

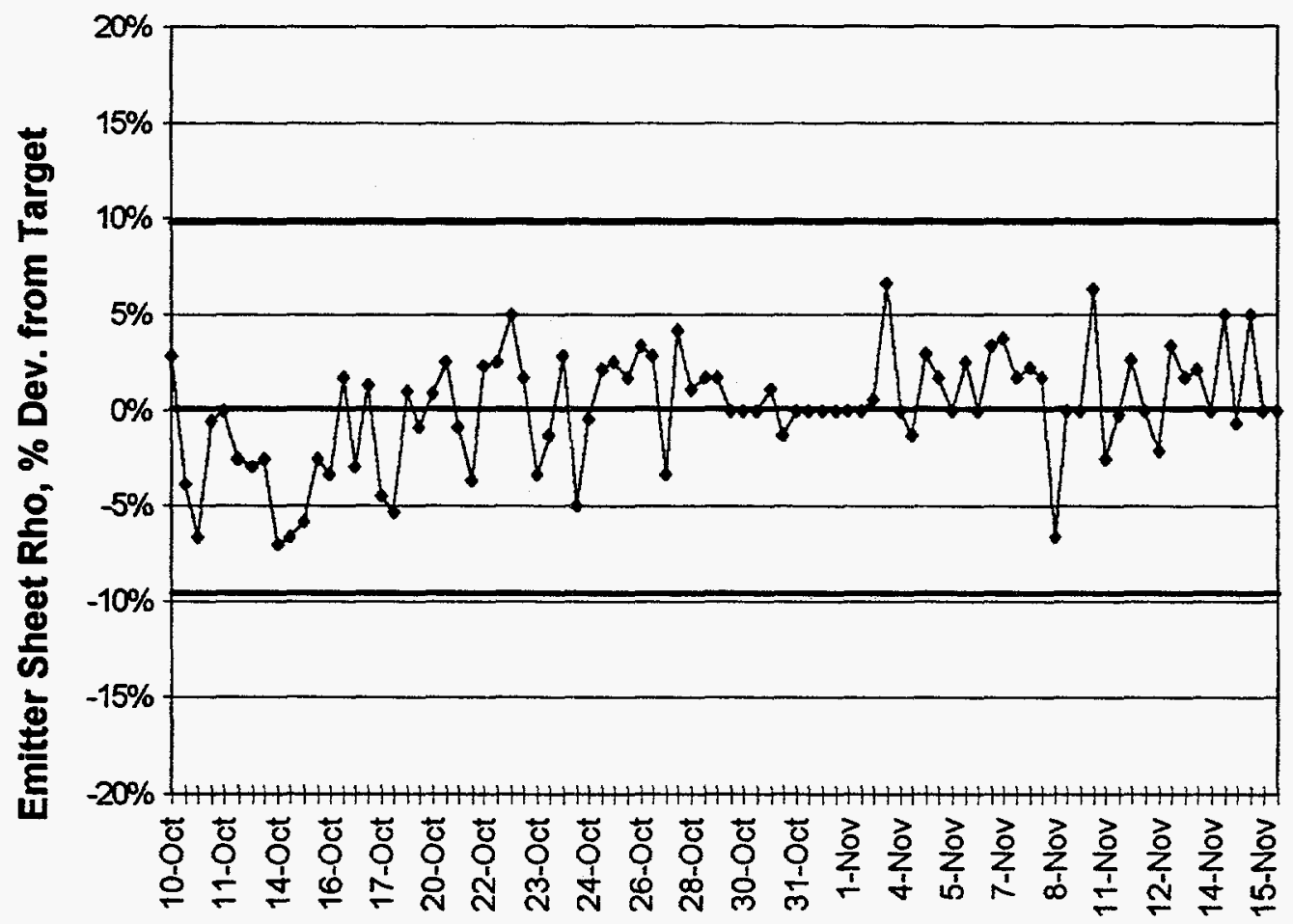

Date

Figure 20. SPC charting of emitter sheet resistance after diffusion.

\section{Statistical Process Control Implementation}

In order to maintain reproducible and reliable photovoltaic manufacturing, key process control points, such as wafer thickness variation, emitter sheet resistance, cell fill factor, lamination defects, etc., must be established. Part of the statement of work of this contract is to identify which measurements are suitable for tracking by statistical process control (SPC), and to implement SPC charting on those points by the end of Phase II. SPC methods are now in use at many sites in the plant, baseline data is being gathered, and a feedback mechanism for early detection of out-of-control process conditions exists. Figure 20 shows an 
SPC chart of emitter sheet resistance after diffusion as an example. The data is characteristic of an incontrol process, well-centered on the target value. The regular charting of data by operators fosters greater participation, and provides a way to monitor progress in bringing a process parameter closer to a target value, tightening the distribution of values, or improving yield. Figure 21 gives an example of a shift in the average value of automatic soldering yield, and distribution tightening, coupled to events in the line.

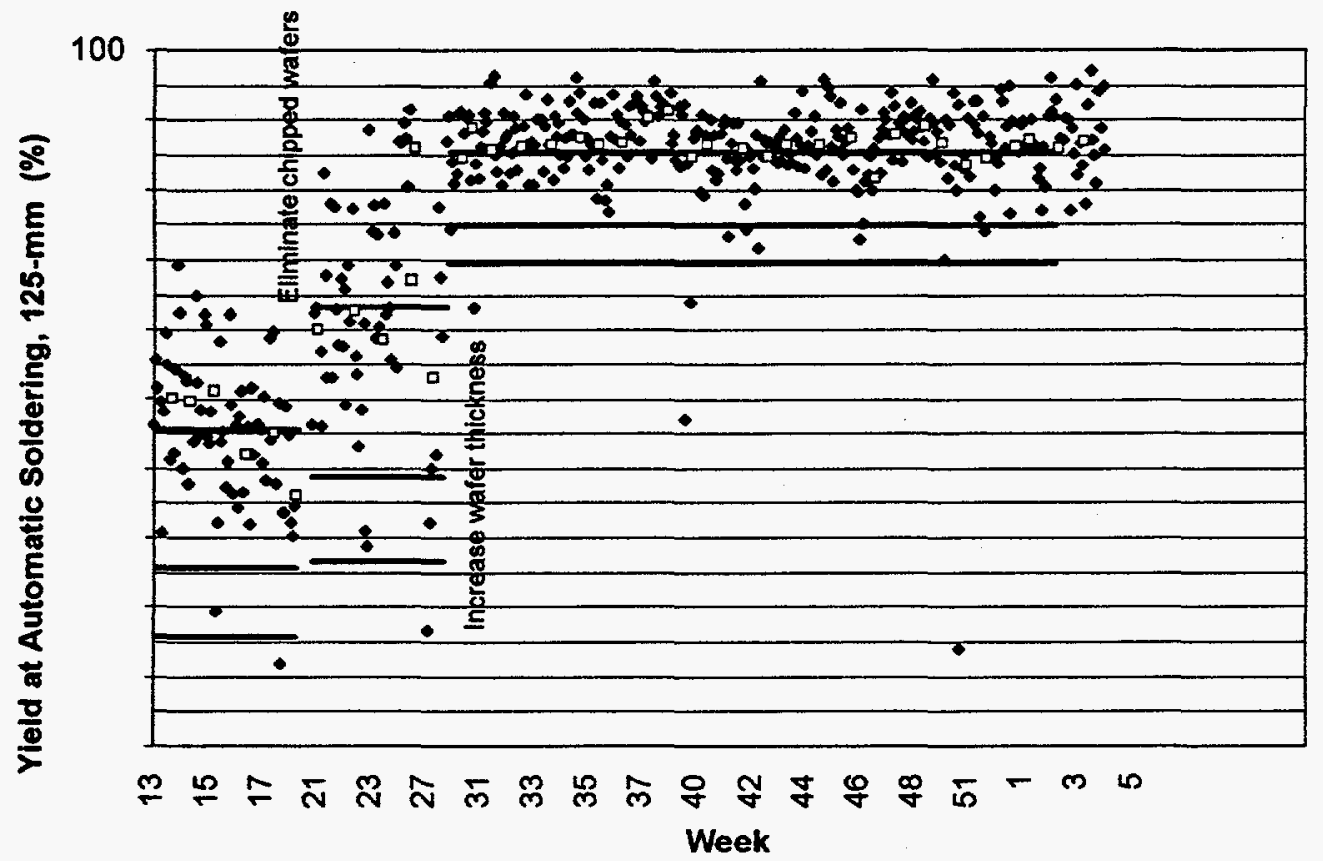

Figure 21. Charting of automatic soldering yield provides feedback mechanism to gauge the effect of process changes.

SPC is best suited for processes in which an operator or engineer has an opportunity to respond to an outof-control condition, by halting the process before further parts are placed at risk, and following an action plan to ascertain the reason for the loss of control. For other processes, for which the effect of the measured parameter on the end product is not yet well understood, it is appropriate to store the measurements in a database which can be used to determine interactions between several process parameters. For still other processes, for which the emphasis is not on control but adherence to a specification limit still needs to be checked, a simple pass/fail measurement may be appropriate, and uses the least labor resources.

Table 2 shows the measurement points in the SSI photovoltaic manufacturing process which have been identified as useful to track by SPC. These points share the feature that action can practically be taken when the measured value strays from its normal range to bring the parameter back into control, or at least to avoid damaging or misprocessing further parts. Many of the points are tracked by manual charting on the part of the operator. This has the advantage of enhancing the visibility of the data and of trends for the operator, as opposed to entering the data in a computer program, and often manual charting is the most appropriate method. Computer entry of measurements for SPC charting is less time consuming, however, thus improving productivity, and several manual SPC points are planned to be converted to computer entry 
in Phase II. SPC has been implemented for over $80 \%$ of the points identified as appropriate in Table 2 , exceeding the goal of $50 \%$ implementation by the end of Phase I. Table 3 shows other measured parameters that are not tracked by SPC, but that are either stored in a database to identify interactions with other parameters, or are used to check manufacturing compliance to documented specifications.

Table 2. Photovoltaic manufacturing control points at SSI appropriate for statistical process control (SPC) tracking.

\begin{tabular}{|c|c|c|c|}
\hline $\begin{array}{l}\text { Process } \\
\text { Area }\end{array}$ & Control Point & $\begin{array}{l}\text { Measured } \\
\text { Data } \\
\text { Charted by } \\
\text { SPC } \\
\text { Manually }\end{array}$ & $\begin{array}{c}\text { Measured } \\
\text { Data } \\
\text { Charted by } \\
\text { SPC on } \\
\text { Computer }\end{array}$ \\
\hline Ingot & Base pressure of crystal growth chamber & $x$ & \\
\hline \multirow[t]{5}{*}{ Wafer } & Wafer thickness & & $\mathrm{X}$ \\
\hline & Thickness variation across wafer & . & $\mathrm{x}$ \\
\hline & Acetic acid concentration & & \\
\hline & Wafer cleaning rewash rate & $\mathrm{x}$ & \\
\hline & Breakage in wafer cleaning & & \\
\hline \multirow[t]{7}{*}{ Cell } & Reject rate for surface defects after wet etch & & \\
\hline & Sheet resistance after diffusion & $\mathrm{X}$ & \\
\hline & Sheet resistance after oxidation & $\mathrm{x}$ & \\
\hline & Breakage in 1 st half of cell fabrication & $\mathrm{x}$ & \\
\hline & AR coating thickness & $\mathrm{X}$ & \\
\hline & Cell fill factor after contact firing & $x$ & \\
\hline & Reproducibility of cell test & $x$ & \\
\hline \multirow[t]{3}{*}{ Module } & Breakage yield in automatic cell soldering & $\mathrm{x}$ & \\
\hline & Yield through circuit assembly & $\mathrm{x}$ & \\
\hline & Reproducibility of module test & $x$ & \\
\hline
\end{tabular}


Table 3. Photovoltaic manufacturing control points at SSI appropriate for check against documented specifications or procedures, and/or for storage in computer database.

\begin{tabular}{|c|c|c|c|}
\hline $\begin{array}{l}\text { Process } \\
\text { Area }\end{array}$ & Control Point & $\begin{array}{l}\text { Measured } \\
\text { Data } \\
\text { Recorded } \\
\text { Manually \& } \\
\text { Checked } \\
\text { Against } \\
\text { Spec. }\end{array}$ & $\begin{array}{l}\text { Measured } \\
\text { Data } \\
\text { Stored in } \\
\text { Computer } \\
\text { Database }\end{array}$ \\
\hline \multirow{13}{*}{ Ingot } & Meltdown time & & $\bar{x}$ \\
\hline & Stabilization time & & $\mathrm{x}$ \\
\hline & Tail length & & $\mathrm{x}$ \\
\hline & Pop diameter at tail & & $\mathrm{x}$ \\
\hline & As-grown ingot diameter & $\mathrm{X}$ & $\mathrm{x}$ \\
\hline & Bulk resistivity of top of ingot & $\mathrm{x}$ & $\mathrm{x}$ \\
\hline & Bulk resistivity of bottom of ingot & $\mathrm{x}$ & $\mathrm{x}$ \\
\hline & Conductivity type (p- or $n$-type) & & \\
\hline & Comer-to-comer diameter & $\mathrm{x}$ & \\
\hline & Flat-to-flat dimension & $\mathrm{x}$ & \\
\hline & Parallelism of flats & $\mathrm{x}$ & \\
\hline & Length of ingot & $\mathrm{x}$ & \\
\hline & $\begin{array}{l}\text { Length of full-diameter ingot lost due to: } \\
\text { bulk resistivity } \\
\text { improper tailing } \\
\text { ingot fracture } \\
\text { diameter }\end{array}$ & & $\begin{array}{l}x \\
x \\
x \\
x\end{array}$ \\
\hline Wafer & Yield through wire sawing/boating & & $\bar{x}$ \\
\hline \multirow[t]{3}{*}{ Cell } & $\begin{array}{l}\text { Breakage in AR coat, printing, contact firing: } \\
\text { cell line with manual belt unload } \\
\text { cell line with automatic belt unload }\end{array}$ & & $\begin{array}{l}x \\
X\end{array}$ \\
\hline & Cell electrical performance & & $\mathrm{x}$ \\
\hline & Yield loss due to low electrical output & & $\mathrm{x}$ \\
\hline \multirow[t]{3}{*}{ Module } & Solder bond pull strength & $\bar{x}$ & \\
\hline & EVA elongation test & $\mathrm{x}$ & \\
\hline & Incidence of laminate defects, by type & & $\mathrm{X}$ \\
\hline
\end{tabular}




\section{Conclusions}

Cost drivers for $\mathrm{Cz}$ Si solar cell modules have been identified. Cost components for existing photovoltaic technology were resolved by process area (ingot, wafer, cell, or module), by direct and indirect materials and labor in each area, and the cost of yield loss in each area was quantified. Cell size and shape, material usage, module size, and cell and module yields have an especially strong influence on cost. A model was developed to show the dependence of module cost per watt on module size, using actual material and labor cost data as inputs. Specific module designs to address cost issues have been implemented, as have numerous other measures to reduce the cost per watt. Broader changes to the module configuration based on the 150-mm-diameter round cell are in progress during Phases II and III.

Wafer breakage is the mechanism which dominates cell yields. Breakage is being reduced by investigation of the factors which affect wafer strength, improved tracking of breakage rate in different processes, enlistment of operator involvement, and development of more robust processes. In the wafering, cell fabrication, and module fabrication areas taken as a whole, yield has increased by 8.5 relative \% in Phase I, in excess of the $5 \%$ goal in the statement of work. The yield in the crystal growth area is not included in this change in yield: the shortage of silicon feedstock during Phase I has forced the use of many nontraditional sources of silicon, most of which seriously compromise crystal growth yield, making it difficult to gauge the effect of efforts to improve ingot yield in this time frame. Productivity measured in terms of $\mathrm{kW}$ produced at the module level per direct labor employee has been improved through automation and development of more efficient work practices. Productivity has increased by $6.5 \%$ in Phase $\mathrm{I}$, exceeding the goal of $5 \%$. The development of systems to ensure compliance and control of module manufacturing includes ISO 9001 certification received by SSI in March 1996, and the ongoing implementation of SPC methods at key control points in manufacturing. Over $80 \%$ of the measurement points identified as appropriate for SPC have been implemented in SSI manufacturing, in excess of the goal of $50 \%$ by the end of Phase I.

As a result of yield gains in wafering, cell, and module fabrication, productivity gains throughout the plant, and design and procurement improvements, items directly related to the PVMaT statement of work sum to greater than $8 \%$ savings in cost per watt at the module level through the end of Phase I, exceeding the $6 \%$ goal for cost reduction. It should be noted that this cost-per-watt savings does not include the negative impact of lower yield in crystal growing in this time frame due to the industry-wide silicon feedstock shortage described above. Module design work and prototyping in Phase I, centered around the cost reduction themes of larger modules, larger cells, and better match of the wafer shape to the ingot cross section, has led to the development of a new, low cost-per-watt module line based on 150-mm-diameter round cells. Implementation and refinement of this module design will be the focus of further cost reductions in Phases II and III. Based on the approach of large modules with 150-mm-diameter round cells, a $19 \%$ reduction in module cost per watt is projected, with production beginning in Phase II. 


\section{References}

Jester, T. (Oct. 1995). PV Cz Silicon Manufacturing Technology Improvements, Final Subcontract Report, 1 April 1992 - 31 May 1995. NREL/TP-411-20016. Work performed by Siemens Solar Industries, Camarillo, CA. Golden, CO: National Renewable Energy Laboratory.

Mitchell, K. W.; King, R. R.; Jester, T. L. (May 1996). "Cz Si Photovoltaics: Towards 100 MW." Conf. Record of the 25th IEEE Photovoltaic Specialists Conference - 1996. Held in Washington, DC, May 13-17, 1996. Piscataway, NJ: Institute of Electrical and Electronics Engineers.

King, R. R.; Mitchell, K. W.; Jester, T. L. (Nov. 1996). "Improvements in Cz Silicon PV Module Manufacturing." NREL/SNL Photovoltaics Program Review, Proceedings of the 14th Conference. Held in Lakewood, CO, Nov. 18-22, 1996. AIP Conf. Proceedings 394. Woodbury, NY: American Institute of Physics. 


\section{REPORT DOCUMENTATION PAGE}

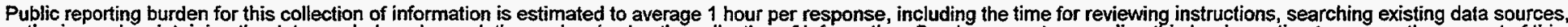

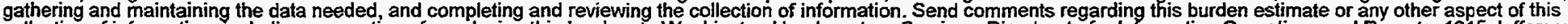

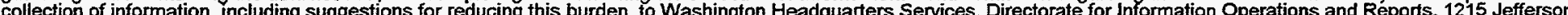

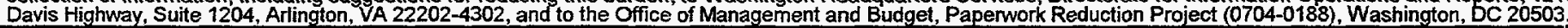

\begin{tabular}{|l|l|l|}
\hline 1. AGENCY USE ONLY (Leave blank) & $\begin{array}{c}\text { 2. REPORT DATE } \\
\text { February } 1998\end{array}$ & $\begin{array}{l}\text { 3. REPORT TYPE AND DATES COVERED } \\
\text { Annual Technical Progress Report, } \\
\text { 9 November } 1995-8 \text { November } 1996\end{array}$
\end{tabular}

\section{TITLE AND SUBTITLE}

Photovoltaic Cz Silicon Module Improvements; Annual Technical Progress Report, 9 November 1995 - 8 November 1996

5. FUNDING NUMBERS

$$
\text { C: ZAF-5-14271-12 }
$$

TA: PV805101

\section{AUTHOR(S)}

R.R. King, K.W. Mitchell, and T.L. Jester

\section{PERFORMING ORGANIZATION NAME(S) AND ADDRESS(ES)}

Siemens Solar Industries

4650 Adohr Lane

Camarillo, CA 93012

9. SPONSORING/MONITORING AGENCY NAME(S) AND ADDRESS(ES)

National Renewable Energy Laboratory

1617 Cole Blvd.

Goiden, CO $80401-3393$

11. SUPPLEMENTARY NOTES

NREL Technical Monitor: R. Mitchell 12b. DISTRIBUTION CODE

UC-1280

13. ABSTRACT (Maximum 200 words)

We describe work focused on reducing the cost per watt of $\mathrm{Cz}$ silicon photovoltaic modules under Phase I of Siemens Solar Industries DOE/NREL PVMaT 4A subcontract. Module cost components are analyzed and solutions to high-cost items are discussed in terms of specific module designs. The approaches of using larger cells and modules to reduce per-part processing cost, and of minimizing yield loss are particularly leveraging. Yield components for various parts of the fabrication process and various types of defects are shou'n, and measurements are given of the force required to break wafers throughout the cell fabrication sequence. The most significant type of manufacturing processes at Siemens Solar Industries is described. Module configurations prototyped during Phase I of this project and scheduled to begin production in Phase II have a projected cost-per-watt reduction of $19 \%$.

14. SUBJECT TERMS

photovoltaics; Photovoltaic Manufacturing Technology; PVMaT; silicon modules ; cost analysis and design ; Czochralski silicon ; manufacturing processes

15. NUMBER OF PAGES

43

16. PRICE CODE

17. SECURITY CLASSIFICATION OF REPORT

Unclassified
18. SECURITY CLASSIFICATION OF THIS PAGE Unclassified
19. SECURITY CLASSIFICATION OF ABSTRACT

Unclassified
20. LIMITATION OF ABSTRACT UL 